CUBO A Mathematical Journal

Vol.20, $N^{-} 01$, (41-64). March 2018

\title{
Common Fixed Point Results in C*-Algebra Valued b-Metric Spaces Via Digraphs
}

\author{
Sushanta Kumar Mohanta \\ Department of Mathematics, \\ West Bengal State University, \\ Barasat, 24 Parganas (North), West Bengal, Kolkata 700126, India. \\ smwbes@yahoo.in
}

\begin{abstract}
We discuss the existence and uniqueness of points of coincidence and common fixed points for a pair of self-mappings defined on a $C^{*}$-algebra valued $b$-metric space endowed with a graph. Our results extend and supplement several recent results in the literature. Strength of hypotheses made in the first result have been weighted through illustrative examples.
\end{abstract}

\section{RESUMEN}

Discutimos la existencia y unicidad de puntos de coincidencia y puntos fijos comumes para un par de aplicaciones definidas en un b-espacio métrico a valores en una álgebra $\mathrm{C}^{*}$ dotado de un grafo en sí mismo. Nuestros resultados extienden y suplementan diversos resultados recientes en la literatura. La fuerza de las hipótesis impuestas al primer resultado se evalúa a través de ejemplos ilustrativos.

Keywords and Phrases: $C^{*}$-algebra, $C^{*}$-algebra valued b-metric, directed graph, $C^{*}$-algebra valued G-contraction, common fixed point.

2010 AMS Mathematics Subject Classification: 54H25, 47H10. 


\section{Introduction}

In 1922 [5], Polish mathematician S. Banach proved a very important result regarding a contraction mapping, known as the Banach contraction principle. This fundamental principle was largely applied in many branches of mathematics. Several authors generalized this interesting theorem in different ways(see [1, 2, 6, 13, 18, 25, 26, 27]). In this context, Bakhtin [4] and Czerwik [1] developed the notion of $b$-metric spaces and proved some fixed point theorems for single-valued and multi-valued mappings in the setting of b-metric spaces. In 2014, Z. Ma et.al.22 introduced the concept of $\mathrm{C}^{*}$-algebra valued metric spaces by using the set of all positive elements of an unital $C^{*}$-algebra instead of the set of real numbers. In [21], the authors introduced another new concept, known as $C^{*}$-algebra valued $b$-metric spaces as a generalization of $C^{*}$-algebra valued metric spaces and b-metric spaces.

In recent investigations, the study of fixed point theory endowed with a graph plays an important role in many aspects. In 2005, Echenique [15] studied fixed point theory by using graphs. After that, Espinola and Kirk [16] applied fixed point results in graph theory. Recently, combining fixed point theory and graph theory, a series of articles(see [3, 8, 9, 10, 20, 24] and references therein) have been dedicated to the improvement of fixed point theory.

The idea of common fixed point was initially given by Junck [19. In fact, the author introduced the concept of weak compatibility and obtained a common fixed point result. Several authors have obtained coincidence points and common fixed points for various classes of mappings on a metric space by using this concept. Motivated by some recent works on the extension of Banach contraction principle to metric spaces with a graph, we reformulated some important common fixed point results in metric spaces to $C^{*}$-algebra valued b-metric spaces endowed with a graph. As some consequences of this study, we deduce several related results in fixed point theory. Finally, some examples are provided to illustrate the results.

\section{Some basic concepts}

We begin with some basic notations, definitions and properties of $\mathrm{C}^{*}$-algebras. Let $\mathbb{A}$ be an unital algebra with the unit $I$. An involution on $\mathbb{A}$ is a conjugate linear map $a \mapsto a^{*}$ on $\mathbb{A}$ such that $\mathrm{a}^{* *}=\mathrm{a}$ and $(\mathrm{ab})^{*}=\mathrm{b}^{*} \mathrm{a}^{*}$ for all $\mathrm{a}, \mathrm{b} \in \mathbb{A}$. The pair $(\mathbb{A}, *)$ is called a $*$-algebra. A Banach $*$-algebra is a $*$-algebra $\mathbb{A}$ together with a complete submultiplicative norm such that $\left\|a^{*}\right\|=\|a\|$ for all $a \in \mathbb{A}$. A $C^{*}$-algebra is a Banach $*$-algebra such that $\left\|a^{*} a\right\|=\|a\|^{2}$ for all $a \in \mathbb{A}$. Let $H$ be a Hilbert space and $\mathrm{B}(\mathrm{H})$, the set of all bounded linear operators on $\mathrm{H}$. Then, under the norm topology, $\mathrm{B}(\mathrm{H})$ is a $\mathrm{C}^{*}$-algebra.

Throughout this discussion, by $\mathbb{A}$ we always denote an unital $\mathrm{C}^{*}$-algebra with the unit I and 
the zero element $\theta$. Set $\mathbb{A}_{h}=\left\{x \in \mathbb{A}: x=x^{*}\right\}$. We call an element $x \in \mathbb{A}$ a positive element, denote it by $x \succeq \theta$, if $x \in \mathbb{A}_{h}$ and $\sigma(x) \subset[0, \infty)$, where $\sigma(x)$ is the spectrum of $x$. Using positive elements, one can define a partial ordering $\preceq$ on $\mathbb{A}_{h}$ as follows:

$$
x \preceq y \text { if and only if } y-x \succeq \theta \text {. }
$$

We shall write $x \prec y$ if $x \preceq y$ and $x \neq y$.

From now on, by $\mathbb{A}_{+}$, we denote the set $\{x \in \mathbb{A}: x \succeq \theta\}$ and by $\mathbb{A}^{\prime}$, we denote the set $\{a \in \mathbb{A}: a b=b a, \forall b \in \mathbb{A}\}$.

Lemma 2.1. 14, 23] Suppose that $\mathbb{A}$ is an unital $\mathrm{C}^{*}$-algebra with a unit I.

(i) For any $x \in \mathbb{A}_{+}$, we have $x \preceq \mathrm{I} \Leftrightarrow\|x\| \leq 1$.

(ii) If $\mathrm{a} \in \mathbb{A}_{+}$with $\|\mathrm{a}\|<\frac{1}{2}$, then $\mathrm{I}-\mathrm{a}$ is invertible and $\left\|\mathrm{a}(\mathrm{I}-\mathrm{a})^{-1}\right\|<1$.

(iii) Suppose that $\mathrm{a}, \mathrm{b} \in \mathbb{A}$ with $\mathrm{a}, \mathrm{b} \succeq \theta$ and $\mathrm{ab}=\mathrm{ba}$, then $\mathrm{ab} \succeq \theta$.

(iv) Let $\mathrm{a} \in \mathbb{A}^{\prime}$, if $\mathrm{b}, \mathrm{c} \in \mathbb{A}$ with $\mathrm{b} \succeq \mathrm{c} \succeq \theta$, and $\mathrm{I}-\mathrm{a} \in \mathbb{A}_{+}^{\prime}$ is an invertible operator, then $(I-a)^{-1} b \succeq(I-a)^{-1} c$.

Remark 2.2. It is worth mentioning that $x \preceq y \Rightarrow\|x\| \leq\|y\|$ for $x, y \in \mathbb{A}_{+}$. In fact, it follows from Lemma 2.1 (i).

Definition 2.3. [22] Let $\mathrm{X}$ be a nonempty set. Suppose the mapping $\mathrm{d}: \mathrm{X} \times \mathrm{X} \rightarrow \mathbb{A}$ satisfies:

(i) $\theta \preceq \mathrm{d}(\mathrm{x}, \mathrm{y})$ for all $\mathrm{x}, \mathrm{y} \in \mathrm{X}$ and $\mathrm{d}(\mathrm{x}, \mathrm{y})=\theta$ if and only if $\mathrm{x}=\mathrm{y}$;

(ii) $\mathrm{d}(x, y)=\mathrm{d}(y, x)$ for all $x, y \in X$;

(iii) $\mathrm{d}(\mathrm{x}, \mathrm{y}) \preceq \mathrm{d}(\mathrm{x}, z)+\mathrm{d}(z, \mathrm{y})$ for all $\mathrm{x}, \mathrm{y}, z \in \mathrm{X}$.

Then $\mathrm{d}$ is called a $\mathrm{C}^{*}$-algebra valued metric on $\mathrm{X}$ and $(\mathrm{X}, \mathbb{A}, \mathrm{d})$ is called a $\mathrm{C}^{*}$-algebra valued metric space.

Definition 2.4. [4] Let $\mathrm{X}$ be a nonempty set and $\mathrm{s} \geq 1$ be a given real number. A function $\mathrm{d}: \mathrm{X} \times \mathrm{X} \rightarrow \mathbb{R}^{+}$is said to be a $\mathrm{b}$-metric on $\mathrm{X}$ if the following conditions hold:

(i) $\mathrm{d}(\mathrm{x}, \mathrm{y})=0$ if and only if $\mathrm{x}=\mathrm{y}$;

(ii) $\mathrm{d}(x, y)=\mathrm{d}(y, x)$ for all $x, y \in X$;

(iii) $\mathrm{d}(\mathrm{x}, \mathrm{y}) \leq \mathrm{s}(\mathrm{d}(\mathrm{x}, z)+\mathrm{d}(z, \mathrm{y}))$ for all $\mathrm{x}, \mathrm{y}, z \in \mathrm{X}$.

The pair $(\mathrm{X}, \mathrm{d})$ is called a $\mathrm{b}$-metric space. 
Definition 2.5. [21] Let $\mathrm{X}$ be a nonempty set and $\mathrm{A} \in \mathbb{A}_{+}^{\prime}$ such that $\mathrm{A} \succeq \mathrm{I}$. Suppose the mapping $\mathrm{d}: \mathrm{X} \times \mathrm{X} \rightarrow \mathbb{A}$ satisfies:

(i) $\theta \preceq \mathrm{d}(\mathrm{x}, \mathrm{y})$ for all $\mathrm{x}, \mathrm{y} \in \mathrm{X}$ and $\mathrm{d}(\mathrm{x}, \mathrm{y})=\theta$ if and only if $\mathrm{x}=\mathrm{y}$;

(ii) $\mathrm{d}(x, y)=\mathrm{d}(\mathrm{y}, \mathrm{x})$ for all $x, y \in X$;

(iii) $\mathrm{d}(\mathrm{x}, \mathrm{y}) \preceq \mathrm{A}(\mathrm{d}(\mathrm{x}, z)+\mathrm{d}(z, \mathrm{y}))$ for all $\mathrm{x}, \mathrm{y}, z \in \mathrm{X}$.

Then $\mathrm{d}$ is called a $\mathrm{C}^{*}$-algebra valued $\mathrm{b}$-metric on $\mathrm{X}$ and $(\mathrm{X}, \mathbb{A}, \mathrm{d})$ is called a $\mathrm{C}^{*}$-algebra valued b-metric space.

It seems important to note that if $\mathbb{A}=\mathbb{C}, A=1$, then the $C^{*}$-algebra valued $b$-metric spaces are just the ordinary metric spaces. Moreover, it is obvious that $C^{*}$-algebra valued $b$-metric spaces generalize the concepts of $\mathrm{C}^{*}$-algebra valued metric spaces and $\mathrm{b}$-metric spaces.

Definition 2.6. [26] Let $(\mathrm{X}, \mathbb{A}, \mathrm{d})$ be a $\mathrm{C}^{*}$-algebra valued $\mathrm{b}$-metric space, $\mathrm{x} \in \mathrm{X}$ and $\left(\mathrm{x}_{\mathrm{n}}\right)$ be a sequence in $\mathrm{X}$. Then

(i) $\left(\mathrm{x}_{\mathrm{n}}\right)$ converges to $\mathrm{x}$ with respect to $\mathbb{A}$ if for any $\epsilon>0$ there is $\mathrm{n}_{0}$ such that for all $\mathrm{n}>\mathrm{n}_{0}$, $\left\|\mathrm{d}\left(\mathrm{x}_{\mathrm{n}}, \mathrm{x}\right)\right\| \leq \epsilon$. We denote it by $\lim _{\mathrm{n} \rightarrow \infty} \mathrm{x}_{\mathrm{n}}=\mathrm{x}$ or $\mathrm{x}_{\mathrm{n}} \rightarrow \mathrm{x}(\mathrm{n} \rightarrow \infty)$.

(ii) $\left(\mathrm{x}_{\mathrm{n}}\right)$ is Cauchy with respect to $\mathbb{A}$ if for any $\epsilon>0$ there is $\mathrm{n}_{0}$ such that for all $\mathrm{n}, \mathrm{m}>\mathrm{n}_{0}$, $\left\|\mathrm{d}\left(\mathrm{x}_{\mathrm{n}}, \mathrm{x}_{\mathrm{m}}\right)\right\| \leq \epsilon$.

(iii) $(\mathrm{X}, \mathbb{A}, \mathrm{d})$ is a complete $\mathrm{C}^{*}$-algebra valued $\mathrm{b}$-metric space if every Cauchy sequence with respect to $\mathbb{A}$ is convergent.

Example 2.7. If $\mathrm{X}$ is a Banach space, then $(\mathrm{X}, \mathbb{A}, \mathrm{d})$ is a complete $\mathrm{C}^{*}$-algebra valued $\mathrm{b}$-metric space with $\mathrm{A}=2^{\mathrm{p}-1} \mathrm{I}$ if we set

$$
\mathrm{d}(x, y)=\|x-y\|^{p} I
$$

where $\mathrm{p}>1$ is a real number. But $(\mathrm{X}, \mathbb{A}, \mathrm{d})$ is not a $\mathrm{C}^{*}$-algebra valued metric space because if $\mathrm{X}=\mathbb{R}$, then $|\mathrm{x}-\mathrm{y}|^{\mathrm{P}} \leq|\mathrm{x}-z|^{\mathfrak{p}}+|z-\mathrm{y}|^{\mathfrak{p}}$ is impossible for all $\mathrm{x}>z>\mathrm{y}$.

Definition 2.8. Let $(\mathrm{X}, \mathrm{A}, \mathrm{d})$ be a $\mathrm{C}^{*}$-algebra valued $\mathrm{b}$-metric space with the coefficient $\mathrm{A} \succeq \mathrm{I}$. We call a mapping $\mathrm{f}: \mathrm{X} \rightarrow \mathrm{X}$ a $\mathrm{C}^{*}$-algebra valued contraction mapping on $\mathrm{X}$ if there exists $\mathrm{B} \in \mathbb{A}$ with $\|\mathrm{B}\|^{2}<\frac{1}{\|\mathrm{~A}\|}$ such that

$$
d(f x, f y) \preceq B^{*} d(x, y) B
$$

for all $\mathrm{x}, \mathrm{y} \in \mathrm{X}$.

Definition 2.9. Let $(\mathrm{X}, \mathbb{A}, \mathrm{d})$ be a $\mathrm{C}^{*}$-algebra valued $\mathrm{b}$-metric space with the coefficient $\mathrm{A} \succeq \mathrm{I}$. A mapping $\mathrm{f}: \mathrm{X} \rightarrow \mathrm{X}$ is called a $\mathrm{C}^{*}$-algebra valued Fisher contraction if there exists $\mathrm{B} \in \mathbb{A}_{+}^{\prime}$ with $\|\mathrm{BA}\|<\frac{1}{\|\mathrm{~A}\|+1}$ such that

$$
d(f x, f y) \preceq B[d(f x, y)+d(f y, x)]
$$

for all $x, y \in X$. 
Definition 2.10. Let $(\mathrm{X}, \mathbb{A}, \mathrm{d})$ be a $\mathrm{C}^{*}$-algebra valued $\mathrm{b}$-metric space with the coefficient $\mathrm{A} \succeq \mathrm{I}$. A mapping $\mathrm{f}: \mathrm{X} \rightarrow \mathrm{X}$ is called a $\mathrm{C}^{*}$-algebra valued Kannan operator if there exists $\mathrm{B} \in \mathbb{A}_{+}^{\prime}$ with $\|\mathrm{B}\|<\frac{1}{\|\mathrm{~A}\|+1}$ such that

$$
d(f x, f y) \preceq B[d(f x, x)+d(f y, y)]
$$

for all $\mathrm{x}, \mathrm{y} \in \mathrm{X}$.

Definition 2.11. [2] Let $\mathrm{T}$ and $\mathrm{S}$ be self mappings of a set $\mathrm{X}$. If $\mathrm{y}=\mathrm{T} \mathrm{x}=\mathrm{Sx}$ for some $\mathrm{x}$ in $\mathrm{X}$, then $\mathrm{x}$ is called a coincidence point of $\mathrm{T}$ and $\mathrm{S}$ and $\mathrm{y}$ is called a point of coincidence of $\mathrm{T}$ and $\mathrm{S}$.

Definition 2.12. [19] The mappings $\mathrm{T}, \mathrm{S}: \mathrm{X} \rightarrow \mathrm{X}$ are weakly compatible, if for every $\mathrm{x} \in \mathrm{X}$, the following holds:

$$
\mathrm{T}(\mathrm{S} x)=\mathrm{S}(\mathrm{T} x) \text { whenever } \mathrm{S} x=\mathrm{T} x .
$$

Proposition 2.13. [2] Let $\mathrm{S}$ and $\mathrm{T}$ be weakly compatible selfmaps of a nonempty set $\mathrm{X}$. If $\mathrm{S}$ and $\mathrm{T}$ have a unique point of coincidence $\mathrm{y}=\mathrm{Sx}=\mathrm{Tx}$, then $\mathrm{y}$ is the unique common fixed point of $\mathrm{S}$ and $\mathrm{T}$.

Definition 2.14. Let $(\mathrm{X}, \mathbb{A}, \mathrm{d})$ be a $\mathrm{C}^{*}$-algebra valued $\mathrm{b}$-metric space with the coefficient $\mathrm{A} \succeq \mathrm{I}$. A mapping $\mathrm{f}: \mathrm{X} \rightarrow \mathrm{X}$ is called $\mathrm{C}^{*}$-algebra valued expansive if there exists $\mathrm{B} \in \mathbb{A}$ with $0<\|\mathrm{B}\|^{2}<$ $\frac{1}{\|\mathrm{~A}\|}$ such that

$$
B^{*} d(f x, f y) B \succeq d(x, y)
$$

for all $\mathrm{x}, \mathrm{y} \in \mathrm{X}$.

We next review some basic notions in graph theory.

Let $(X, \mathbb{A}, d)$ be a $C^{*}$-algebra valued $b$-metric space. Let $G$ be a directed graph (digraph) with a set of vertices $V(G)=X$ and a set of edges $E(G)$ contains all the loops, i.e., $E(G) \supseteq \Delta$, where $\Delta=\{(x, x): x \in X\}$. We also assume that $G$ has no parallel edges and so we can identify $\mathrm{G}$ with the pair $(V(G), E(G))$. $G$ may be considered as a weighted graph by assigning to each edge the distance between its vertices. By $\mathrm{G}^{-1}$ we denote the graph obtained from $\mathrm{G}$ by reversing the direction of edges i.e., $E\left(G^{-1}\right)=\{(x, y) \in X \times X:(y, x) \in E(G)\}$. Let $\tilde{G}$ denote the undirected graph obtained from $G$ by ignoring the direction of edges. Actually, it will be more convenient for us to treat $\tilde{G}$ as a directed graph for which the set of its edges is symmetric. Under this convention,

$$
E(\tilde{G})=E(G) \cup E\left(G^{-1}\right) .
$$

Our graph theory notations and terminology are standard and can be found in all graph theory books, like [7, 12, 17]. If $x, y$ are vertices of the digraph $G$, then a path in $G$ from $x$ to $y$ of length $n(n \in \mathbb{N})$ is a sequence $\left(x_{i}\right)_{i=0}^{n}$ of $n+1$ vertices such that $x_{0}=x, x_{n}=y$ and $\left(x_{i-1}, x_{i}\right) \in E(G)$ for $i=1,2, \cdots, n$. A graph $G$ is connected if there is a path between any two vertices of $G$. $G$ is weakly connected if $\tilde{G}$ is connected. 
Definition 2.15. Let $(\mathrm{X}, \mathrm{A}, \mathrm{d})$ be a $\mathrm{C}^{*}$-algebra valued $\mathrm{b}$-metric space with the coefficient $\mathrm{A} \succeq \mathrm{I}$ and let $\mathrm{G}=(\mathrm{V}(\mathrm{G}), \mathrm{E}(\mathrm{G}))$ be a graph. A mapping $\mathrm{f}: \mathrm{X} \rightarrow \mathrm{X}$ is called a $\mathrm{C}^{*}$-algebra valued $\mathrm{G}$ contraction if there exists $a \mathrm{~B} \in \mathbb{A}$ with $\|\mathrm{B}\|^{2}<\frac{1}{\|\mathrm{~A}\|}$ such that

$$
d(f x, f y) \preceq B^{*} d(x, y) B
$$

for all $x, y \in X$ with $(x, y) \in E(G)$.

Any $\mathrm{C}^{*}$-algebra valued contraction mapping on $\mathrm{X}$ is a $\mathrm{G}_{0}$-contraction, where $\mathrm{G}_{0}$ is the complete graph defined by $(X, X \times X)$. But it is worth mentioning that a $C^{*}$-algebra valued $G$-contraction need not be a $C^{*}$-algebra valued contraction (see Remark 3.23).

Definition 2.16. Let $(\mathrm{X}, \mathbb{A}, \mathrm{d})$ be a $\mathrm{C}^{*}$-algebra valued $\mathrm{b}$-metric space with the coefficient $\mathrm{A} \succeq \mathrm{I}$ and let $\mathrm{G}=\left(\mathrm{V}(\mathrm{G}), \mathrm{E}(\mathrm{G})\right.$ ) be a graph. A mapping $\mathrm{f}: \mathrm{X} \rightarrow \mathrm{X}$ is called $\mathrm{C}^{*}$-algebra valued Fisher $\mathrm{G}$-contraction if there exists $\mathrm{B} \in \mathbb{A}_{+}^{\prime}$ with $\|\mathrm{BA}\|<\frac{1}{\|\mathrm{~A}\|+1}$ such that

$$
d(f x, f y) \preceq B[d(f x, y)+d(f y, x)]
$$

for all $x, y \in X$ with $(x, y) \in E(G)$.

It is easy to observe that a $\mathrm{C}^{*}$-algebra valued Fisher contraction is a $\mathrm{C}^{*}$-algebra valued Fisher $\mathrm{G}_{0}$-contraction. But it is important to note that a $\mathrm{C}^{*}$-algebra valued Fisher $\mathrm{G}$-contraction need not be a $\mathrm{C}^{*}$-algebra valued Fisher contraction. The following example supports the above remark.

Example 2.17. Let $\mathrm{X}=[0, \infty)$ and $\mathrm{B}(\mathrm{H})$ be the set of all bounded linear operators on a Hilbert space $\mathrm{H}$. Define $\mathrm{d}: \mathrm{X} \times \mathrm{X} \rightarrow \mathrm{B}(\mathrm{H})$ by $\mathrm{d}(\mathrm{x}, \mathrm{y})=|\mathrm{x}-\mathrm{y}|^{2}$ I for all $\mathrm{x}, \mathrm{y} \in \mathrm{X}$. Then $(\mathrm{X}, \mathrm{B}(\mathrm{H}), \mathrm{d})$ is a $\mathrm{C}^{*}$-algebra valued $\mathrm{b}$-metric space with the coefficient $\mathrm{A}=2 \mathrm{I}$. Let $\mathrm{G}$ be a digraph such that $\mathrm{V}(\mathrm{G})=\mathrm{X}$ and $\mathrm{E}(\mathrm{G})=\Delta \cup\left\{\left(3^{\mathrm{t}} x, 3^{\mathrm{t}}(\mathrm{x}+1)\right): \mathrm{x} \in \mathrm{X}\right.$ with $\left.\mathrm{x} \geq 2, \mathrm{t}=0,1,2, \cdots\right\}$.

Let $\mathrm{f}: \mathrm{X} \rightarrow \mathrm{X}$ be defined by $\mathrm{fx}=3 \mathrm{x}$ for all $\mathrm{x} \in \mathrm{X}$.

For $\mathrm{x}=3^{\mathrm{t}} z, \mathrm{y}=3^{\mathrm{t}}(z+1), z \geq 2$, we have

$$
\begin{aligned}
\mathrm{d}(\mathrm{f} x, \mathrm{fy}) & =\mathrm{d}\left(3^{\mathrm{t}+1} z, 3^{\mathrm{t}+1}(z+1)\right) \\
& =3^{2 \mathrm{t}+2} \mathrm{I} \\
& \preceq \frac{9}{58} 3^{2 \mathrm{t}}\left(8 z^{2}+8 z+10\right) \mathrm{I} \\
& =B\left[\mathrm{~d}\left(3^{\mathrm{t}+1} z, 3^{\mathrm{t}}(z+1)\right)+\mathrm{d}\left(3^{\mathrm{t}+1}(z+1), 3^{\mathrm{t}} z\right)\right] \\
& =B[d(f x, y)+d(f y, x)]
\end{aligned}
$$

where $\mathrm{B}=\frac{9}{58} \mathrm{I} \in \mathrm{B}(\mathrm{H})_{+}^{\prime}$ with $\|\mathrm{BA}\|<\frac{1}{\|\mathrm{~A}\|+1}$. Thus, $\mathrm{f}$ is a $\mathrm{C}^{*}$-algebra valued Fisher $\mathrm{G}$-contraction.

We now verify that $\mathrm{f}$ is not a $\mathrm{C}^{*}$-algebra valued Fisher contraction. In fact, if $\mathrm{x}=3, \mathrm{y}=0$, 
then for any arbitrary $\mathrm{B} \in \mathrm{B}(\mathrm{H})_{+}^{\prime}$ with $\|\mathrm{BA}\|<\frac{1}{\|\mathrm{~A}\|+1}=\frac{1}{3}$ (which implies $3 \mathrm{BA} \prec \mathrm{I}$ ), we have

$$
\begin{aligned}
B[d(f x, y)+d(f y, x)] & =B[d(f 3,0)+d(f 0,3)] \\
& =90 B I \\
& =45 B A \\
& =\frac{5}{27}(3 B A)(81 I) \\
& \prec 81 I \\
& =d(f x, f y) .
\end{aligned}
$$

Definition 2.18. Let $(\mathrm{X}, \mathbb{A}, \mathrm{d})$ be a $\mathrm{C}^{*}$-algebra valued $\mathrm{b}$-metric space with the coefficient $\mathrm{A} \succeq \mathrm{I}$ and let $\mathrm{G}=\left(\mathrm{V}(\mathrm{G}), \mathrm{E}(\mathrm{G})\right.$ ) be a graph. A mapping $\mathrm{f}: \mathrm{X} \rightarrow \mathrm{X}$ is called $\mathrm{C}^{*}$-algebra valued $\mathrm{G}$-Kannan if there exists $\mathrm{B} \in \mathbb{A}_{+}^{\prime}$ with $\|\mathrm{B}\|<\frac{1}{\|\mathrm{~A}\|+1}$ such that

$$
d(f x, f y) \preceq B[d(f x, x)+d(f y, y)]
$$

for all $x, y \in X$ with $(x, y) \in E(G)$.

Note that any $\mathrm{C}^{*}$-algebra valued Kannan operator is $\mathrm{C}^{*}$-algebra valued $\mathrm{G}_{0}$-Kannan. However, a $\mathrm{C}^{*}$-algebra valued G-Kannan operator need not be a $\mathrm{C}^{*}$-algebra valued Kannan operator (see Remark 3.28).

Remark 2.19. If $\mathrm{f}$ is a $\mathrm{C}^{*}$-algebra valued $\mathrm{G}$-contraction(resp., $\mathrm{G}$-Kannan or Fisher $\mathrm{G}$-contraction), then $\mathrm{f}$ is both a $\mathrm{C}^{*}$-algebra valued $\mathrm{G}^{-1}$-contraction(resp., $\mathrm{G}^{-1}$-Kannan or Fisher $\mathrm{G}^{-1}$-contraction) and a $\mathrm{C}^{*}$-algebra valued $\tilde{\mathrm{G}}$-contraction(resp., $\tilde{\mathrm{G}}-$ Kannan or Fisher $\tilde{\mathrm{G}}$-contraction).

\section{Main Results}

In this section we always assume that $(X, \mathbb{A}, d)$ is a $C^{*}$-algebra valued $b$-metric space with the coefficient $A \succeq I$ and $G$ is a directed graph such that $V(G)=X$ and $E(G) \supseteq \Delta$.

Let $f, g: X \rightarrow X$ be such that $f(X) \subseteq g(X)$. If $x_{0} \in X$ is arbitrary, then there exists an element $x_{1} \in X$ such that $f x_{0}=g x_{1}$, since $f(X) \subseteq g(X)$. Proceeding in this way, we can construct a sequence $\left(g x_{n}\right)$ such that $g x_{n}=f x_{n-1}, n=1,2,3, \cdots$.

Definition 3.1. Let $(\mathrm{X}, \mathbb{A}, \mathrm{d})$ be a $\mathrm{C}^{*}$-algebra valued $\mathrm{b}$-metric space endowed with a graph $\mathrm{G}$ and $\mathrm{f}, \mathrm{g}: \mathrm{X} \rightarrow \mathrm{X}$ be such that $\mathrm{f}(\mathrm{X}) \subseteq \mathrm{g}(\mathrm{X})$. We define $\mathrm{C}_{\mathrm{g} f}$ the set of all elements $\mathrm{x}_{\mathrm{o}}$ of $\mathrm{X}$ such that $\left(\mathrm{g} \mathrm{x}_{\mathrm{n}}, \mathrm{g} \mathrm{x}_{\mathrm{m}}\right) \in \mathrm{E}(\tilde{\mathrm{G}})$ for $\mathrm{m}, \mathrm{n}=0,1,2, \cdots$ and for every sequence $\left(\mathrm{gx_{ \textrm {n } }}\right)$ such that $\mathrm{g} \mathrm{x}_{\mathrm{n}}=\mathrm{f} \mathrm{x}_{\mathrm{n}-1}$.

If $g=I$, the identity map on $X$, then obviously $C_{g f}$ becomes $C_{f}$ which is the collection of all elements $x$ of $X$ such that $\left(f^{n} x, f^{m} x\right) \in E(\tilde{G})$ for $m, n=0,1,2, \cdots$. 
Theorem 3.2. Let $(\mathrm{X}, \mathbb{A}, \mathrm{d})$ be a $\mathrm{C}^{*}$-algebra valued $\mathrm{b}$-metric space endowed with a graph $\mathrm{G}$ and the mappings $\mathrm{f}, \mathrm{g}: \mathrm{X} \rightarrow \mathrm{X}$ be such that

$$
d(f x, f y) \preceq B^{*} d(g x, g y) B
$$

for all $\mathrm{x}, \mathrm{y} \in \mathrm{X}$ with $(\mathrm{gx}, \mathrm{gy}) \in \mathrm{E}(\tilde{\mathrm{G}})$, where $\mathrm{B} \in \mathbb{A}$ and $\|\mathrm{B}\|^{2}<\frac{1}{\|\mathrm{~A}\|}$. Suppose $\mathrm{f}(\mathrm{X}) \subseteq \mathrm{g}(\mathrm{X})$ and $\mathrm{g}(\mathrm{X})$ is a complete subspace of $\mathrm{X}$ with the following property:

(*) If $\left(\mathrm{gx}_{\mathrm{n}}\right)$ is a sequence in $\mathrm{X}$ such that $\mathrm{gx} \mathrm{n} \rightarrow \mathrm{x}$ and $\left(\mathrm{gx}, \mathrm{g} \mathrm{x}_{\mathrm{n}+1}\right) \in \mathrm{E}(\tilde{\mathrm{G}})$ for all $\mathrm{n} \geq 1$,

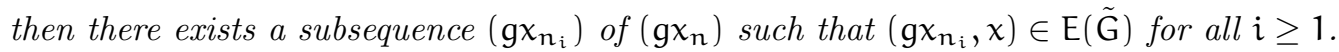

Then $\mathrm{f}$ and $\mathrm{g}$ have a point of coincidence in $\mathrm{X}$ if $\mathrm{C}_{\mathrm{g}} \neq \emptyset$. Moreover, $\mathrm{f}$ and $\mathrm{g}$ have a unique point of coincidence in $\mathrm{X}$ if the graph $\mathrm{G}$ has the following property:

(**) If $\mathrm{x}, \mathrm{y}$ are points of coincidence of $\mathrm{f}$ and $\mathrm{g}$ in $\mathrm{X}$, then $(\mathrm{x}, \mathrm{y}) \in \mathrm{E}(\tilde{\mathrm{G}})$.

Furthermore, if $\mathrm{f}$ and $\mathrm{g}$ are weakly compatible, then $\mathrm{f}$ and $\mathrm{g}$ have a unique common fixed point in $\mathrm{X}$.

Proof. Suppose that $C_{g f} \neq \emptyset$. We choose an $x_{0} \in C_{g f}$ and keep it fixed. Since $f(X) \subseteq g(X)$, there exists a sequence $\left(g x_{n}\right)$ such that $g x_{n}=f x_{n-1}, n=1,2,3, \cdots$ and $\left(g x_{n}, g x_{m}\right) \in E(\tilde{G})$ for $\mathrm{m}, \mathrm{n}=0,1,2, \cdots$.

It is a well known fact that in a $C^{*}$-algebra $\mathbb{A}$, if $a, b \in \mathbb{A}_{+}$and $a \preceq b$, then for any $x \in \mathbb{A}$ both $x^{*} a x$ and $x^{*} b x$ are positive elements and $x^{*} a x \preceq x^{*} b x[23$

For any $\mathrm{n} \in \mathbb{N}$, we have by using condition (3.1) that

$$
d\left(g x_{n}, g x_{n+1}\right)=d\left(f x_{n-1}, f x_{n}\right) \preceq B^{*} d\left(g x_{n-1}, g x_{n}\right) B .
$$

By repeated use of condition (3.2), we get

$$
d\left(g x_{n}, g x_{n+1}\right) \preceq\left(B^{*}\right)^{n} d\left(g x_{0}, g x_{1}\right) B^{n}=\left(B^{n}\right)^{*} B_{0} B^{n},
$$

for all $\mathrm{n} \in \mathbb{N}$, where $\mathrm{B}_{0}=\mathrm{d}\left(g \mathrm{x}_{0}, g \mathrm{x}_{1}\right) \in \mathbb{A}_{+}$. 
For any $m, n \in \mathbb{N}$ with $m>n$, we have by using condition (3.3) that

$$
\begin{aligned}
d\left(g x_{n}, g x_{m}\right) \preceq & A\left[d\left(g x_{n}, g x_{n+1}\right)+d\left(g x_{n+1}, g x_{m}\right)\right] \\
\preceq & A d\left(g x_{n}, g x_{n+1}\right)+A^{2} d\left(g x_{n+1}, g x_{n+2}\right)+\cdots \\
& +A^{m-n-1} d\left(g x_{m-2}, g x_{m-1}\right)+A^{m-n-1} d\left(g x_{m-1}, g x_{m}\right) \\
\preceq & A\left(B^{*}\right)^{n} B_{0} B^{n}+A^{2}\left(B^{*}\right)^{n+1} B_{0} B^{n+1}+A^{3}\left(B^{*}\right)^{n+2} B_{0} B^{n+2}+\cdots \\
& +A^{m-n-1}\left(B^{*}\right)^{m-2} B_{0} B^{m-2}+A^{m-n-1}\left(B^{*}\right)^{m-1} B_{0} B^{m-1} \\
\preceq & \sum_{k=1}^{m-n-1} A^{k}\left(B^{*}\right)^{n+k-1} B_{0} B^{n+k-1}+A^{m-n}\left(B^{*}\right)^{m-1} B_{0} B^{m-1} \\
= & \sum_{k=1}^{m-n} A^{k}\left(B^{*}\right)^{n+k-1} B_{0} B^{n+k-1} \\
\preceq & \sum_{k=1}^{m-n}\left\|A^{k}\left(B^{*}\right)^{n+k-1} B_{0} B^{n+k-1}\right\| I \\
\preceq & \left\|B_{0}\right\| \sum_{k=1}^{m-n}\|A\|^{k}\|B\|^{2(n+k-1)} I \\
= & \left\|B_{0}\right\|\|B\|^{2 n}\|A\| \sum_{k=1}^{m-n}\left(\|A\|\|B\|^{2}\right)^{k-1} I \\
\preceq & \left\|B_{0}\right\|\|B\|^{2 n}\|A\|\left\|_{1}\right\| A\|B\|^{2} \text { since }\|B\|^{2}<\frac{1}{\|A\|} \\
\rightarrow & \theta \text { as } n \rightarrow \infty .
\end{aligned}
$$

Therefore, $\left(g x_{n}\right)$ is a Cauchy sequence with respect to $\mathbb{A}$. Since $g(X)$ is complete, there exists an $u \in g(X)$ such that $\lim _{n \rightarrow \infty} g x_{n}=u=g v$ for some $v \in X$.

As $x_{0} \in C_{g f}$, it follows that $\left(g x_{n}, g x_{n+1}\right) \in E(\tilde{G})$ for all $n \geq 0$, and so by property $(*)$, there exists a subsequence $\left(g x_{n_{i}}\right)$ of $\left(g x_{n}\right)$ such that $\left(g x_{n_{i}}, g v\right) \in E(\tilde{G})$ for all $i \geq 1$.

Using condition (3.1), we have

$$
\begin{aligned}
\mathrm{d}(f v, g v) & \preceq A\left[d\left(f v, f x_{n_{i}}\right)+d\left(f x_{n_{i}}, g v\right)\right] \\
& \preceq A B^{*} d\left(g v, g x_{n_{i}}\right) B+A d\left(g x_{n_{i}+1}, g v\right) \\
& \rightarrow \theta \text { as } i \rightarrow \infty .
\end{aligned}
$$

This implies that $d(f v, g v)=\theta$ and hence $f v=g v=u$. Therefore, $u$ is a point of coincidence of $f$ and $g$.

The next is to show that the point of coincidence is unique. Assume that there is another point of coincidence $u^{*}$ in $X$ such that $f x=g x=u^{*}$ for some $x \in X$. By property $(* *)$, we have 
$\left(u, u^{*}\right) \in E(\tilde{G})$. Then,

$$
\begin{aligned}
d\left(u, u^{*}\right) & =d(f v, f x) \\
\preceq & B^{*} d(g v, g x) B \\
& =B^{*} d\left(u, u^{*}\right) B
\end{aligned}
$$

which implies that,

$$
\begin{aligned}
\left\|d\left(u, u^{*}\right)\right\| & \leq\left\|B^{*} d\left(u, u^{*}\right) B\right\| \\
& \leq\left\|B^{*}\right\|\left\|d\left(u, u^{*}\right)\right\|\|B\| \\
& =\|B\|^{2}\left\|d\left(u, u^{*}\right)\right\| .
\end{aligned}
$$

Since $\|B\|^{2}<\frac{1}{\|A\|} \leq 1$, it follows that $d\left(u, u^{*}\right)=\theta$ i.e., $u=u^{*}$. Therefore, $f$ and $g$ have a unique point of coincidence in $X$.

If $f$ and $g$ are weakly compatible, then by Proposition 2.13, $f$ and $g$ have a unique common fixed point in $X$.

The following corollary gives fixed point of Banach G-contraction in $C^{*}$-algebra valued bmetric spaces.

Corollary 3.3. Let $(\mathrm{X}, \mathbb{A}, \mathrm{d})$ be a complete $\mathrm{C}^{*}$-algebra valued $\mathrm{b}$-metric space endowed with a graph $\mathrm{G}$ and the mapping $\mathrm{f}: \mathrm{X} \rightarrow \mathrm{X}$ be such that

$$
d(f x, f y) \preceq B^{*} d(x, y) B
$$

for all $\mathrm{x}, \mathrm{y} \in \mathrm{X}$ with $(\mathrm{x}, \mathrm{y}) \in \mathrm{E}(\tilde{\mathrm{G}})$, where $\mathrm{B} \in \mathbb{A}$ with $\|\mathrm{B}\|^{2}<\frac{1}{\|\mathrm{~A}\|}$. Suppose $(\mathrm{X}, \mathbb{A}, \mathrm{d}, \mathrm{G})$ has the following property:

(*) If $\left(\mathrm{x}_{\mathrm{n}}\right)$ is a sequence in $\mathrm{X}$ such that $\mathrm{x}_{\mathrm{n}} \rightarrow \mathrm{x}$ and $\left(\mathrm{x}_{\mathrm{n}}, \mathrm{x}_{\mathrm{n}+1}\right) \in \mathrm{E}(\tilde{\mathrm{G}})$ for all $\mathrm{n} \geq 1$, then there exists a subsequence $\left(\mathrm{x}_{\mathrm{n}_{\mathrm{i}}}\right)$ of $\left(\mathrm{x}_{\mathrm{n}}\right)$ such that $\left(\mathrm{x}_{\mathrm{n}_{\mathrm{i}}}, \mathrm{x}\right) \in \mathrm{E}(\tilde{\mathrm{G}})$ for all $\mathrm{i} \geq 1$.

Then $\mathrm{f}$ has a fixed point in $\mathrm{X}$ if $\mathrm{C}_{\mathrm{f}} \neq \emptyset$. Moreover, $\mathrm{f}$ has a unique fixed point in $\mathrm{X}$ if the graph $\mathrm{G}$ has the following property:

$$
(* *)^{\prime} \text { If } \mathrm{x}, \mathrm{y} \text { are fixed points of } \mathrm{f} \text { in } \mathrm{X} \text {, then }(\mathrm{x}, \mathrm{y}) \in \mathrm{E}(\tilde{\mathrm{G}}) \text {. }
$$

Proof. The proof can be obtained from Theorem 3.2 by considering $g=\mathrm{I}$, the identity map on $\mathrm{X}$.

Corollary 3.4. Let $(\mathrm{X}, \mathbb{A}, \mathrm{d})$ be a $\mathrm{C}^{*}$-algebra valued $\mathrm{b}$-metric space and the mappings $\mathrm{f}, \mathrm{g}: \mathrm{X} \rightarrow$ $\mathrm{X}$ be such that (3.1) holds for all $\mathrm{x}, \mathrm{y} \in \mathrm{X}$, where $\mathrm{B} \in \mathbb{A}$ with $\|\mathrm{B}\|^{2}<\frac{1}{\|\mathrm{~A}\|}$. If $\mathrm{f}(\mathrm{X}) \subseteq \mathrm{g}(\mathrm{X})$ and 
$\mathrm{g}(\mathrm{X})$ is a complete subspace of $\mathrm{X}$, then $\mathrm{f}$ and $\mathrm{g}$ have a unique point of coincidence in $\mathrm{X}$. Moreover, if $\mathrm{f}$ and $\mathrm{g}$ are weakly compatible, then $\mathrm{f}$ and $\mathrm{g}$ have a unique common fixed point in $\mathrm{X}$.

Proof. The proof follows from Theorem 3.2 by taking $G=G_{0}$, where $G_{0}$ is the complete graph $(\mathrm{X}, \mathrm{X} \times \mathrm{X})$.

The following corollary is analogue of Banach Contraction Principle.

Corollary 3.5. Let $(\mathrm{X}, \mathbb{A}, \mathrm{d})$ be a complete $\mathrm{C}^{*}$-algebra valued $\mathrm{b}$-metric space and the mapping $\mathrm{f}: \mathrm{X} \rightarrow \mathrm{X}$ be such that (3.4) holds for all $\mathrm{x}, \mathrm{y} \in \mathrm{X}$, where $\mathrm{B} \in \mathbb{A}$ with $\|\mathrm{B}\|^{2}<\frac{1}{\|\mathrm{~A}\|}$. Then $\mathrm{f}$ has a unique fixed point $\mathrm{u}$ in $\mathrm{X}$ and $\mathrm{f}^{\mathrm{n}} \mathrm{x} \rightarrow \mathrm{u}$ for all $\mathrm{x} \in \mathrm{X}$.

Proof. It follows from Theorem 3.2 by putting $\mathrm{G}=\mathrm{G}_{0}$ and $\mathrm{g}=\mathrm{I}$.

Remark 3.6. We observe that Banach contraction theorem in a complete metric space can be obtained from Corollary 3.5 by taking $\mathbb{A}=\mathbb{C}, A=1$. Thus, Theorem 3.2 is a generalization of Banach contraction theorem in metric spaces to $\mathrm{C}^{*}$-algebra valued $\mathrm{b}$-metric spaces.

From Theorem 3.2, we obtain the following corollary concerning the fixed point of expansive mapping in $\mathrm{C}^{*}$-algebra valued $\mathrm{b}$-metric spaces.

Corollary 3.7. Let $(\mathrm{X}, \mathbb{A}, \mathrm{d})$ be a complete $\mathrm{C}^{*}$-algebra valued $\mathrm{b}$-metric space and let $\mathrm{g}: \mathrm{X} \rightarrow \mathrm{X}$ be an onto mapping satisfying

$$
\mathrm{B}^{*} \mathrm{~d}(\mathrm{gx}, \mathrm{gy}) \mathrm{B} \succeq \mathrm{d}(\mathrm{x}, \mathrm{y})
$$

for all $\mathrm{x}, \mathrm{y} \in \mathrm{X}$, where $\mathrm{B} \in \mathbb{A}$ with $\|\mathrm{B}\|^{2}<\frac{1}{\|\mathrm{~A}\|}$. Then $\mathrm{g}$ has a unique fixed point in $\mathrm{X}$.

Proof. The conclusion of the corollary follows from Theorem 3.2 by taking $G=G_{0}$ and $f=I$.

Corollary 3.8. Let $(\mathrm{X}, \mathbb{A}, \mathrm{d})$ be a complete $\mathrm{C}^{*}$-algebra valued $\mathrm{b}$-metric space endowed with a partial ordering $\sqsubseteq$ and the mapping $\mathrm{f}: \mathrm{X} \rightarrow \mathrm{X}$ be such that (3.4) holds for all $\mathrm{x}, \mathrm{y} \in \mathrm{X}$ with $\mathrm{x} \sqsubseteq \mathrm{y}$ or, $\mathrm{y} \sqsubseteq \mathrm{x}$, where $\mathrm{B} \in \mathbb{A}$ and $\|\mathrm{B}\|^{2}<\frac{1}{\|\mathrm{~A}\|}$. Suppose $(\mathrm{X}, \mathbb{A}, \mathrm{d}, \sqsubseteq)$ has the following property:

(†) If $\left(\mathrm{x}_{\mathrm{n}}\right)$ is a sequence in $\mathrm{X}$ such that $\mathrm{x}_{\mathrm{n}} \rightarrow \mathrm{x}$ and $\mathrm{x}_{\mathrm{n}}, \mathrm{x}_{\mathrm{n}+1}$ are comparable for all $\mathrm{n} \geq 1$, then there exists a subsequence $\left(\mathrm{x}_{n_{i}}\right)$ of $\left(\mathrm{x}_{\mathrm{n}}\right)$ such that $\mathrm{x}_{\mathrm{n}_{i}}, \mathrm{x}$ are comparable for all $\mathrm{i} \geq 1$. If there exists $\mathrm{x}_{0} \in \mathrm{X}$ such that $\mathrm{f}^{\mathrm{n}} \mathrm{x}_{0}, \mathrm{f}^{\mathrm{m}} \mathrm{x}_{0}$ are comparable for $\mathrm{m}, \mathrm{n}=0,1,2, \cdots$, then $\mathrm{f}$ has a fixed point in X. Moreover, $\mathrm{f}$ has a unique fixed point in $\mathrm{X}$ if the following property holds:

( $\dagger \dagger$ ) If $\mathrm{x}, \mathrm{y}$ are fixed points of $\mathrm{f}$ in $\mathrm{X}$, then $\mathrm{x}, \mathrm{y}$ are comparable.

Proof. The proof can be obtained from Theorem 3.2 by taking $\mathrm{g}=\mathrm{I}$ and $\mathrm{G}=\mathrm{G}_{2}$, where the graph $\mathrm{G}_{2}$ is defined by $\mathrm{E}\left(\mathrm{G}_{2}\right)=\{(\mathrm{x}, \mathrm{y}) \in \mathrm{X} \times \mathrm{X}: \mathrm{x} \sqsubseteq \mathrm{y}$ or $\mathrm{y} \sqsubseteq \mathrm{x}\}$. 
Theorem 3.9. Let $(\mathrm{X}, \mathbb{A}, \mathrm{d})$ be a $\mathrm{C}^{*}$-algebra valued $\mathrm{b}$-metric space endowed with a graph $\mathrm{G}$ and the mappings $\mathrm{f}, \mathrm{g}: \mathrm{X} \rightarrow \mathrm{X}$ be such that

$$
d(f x, f y) \preceq B[d(f x, g y)+d(f y, g x)]
$$

for all $\mathrm{x}, \mathrm{y} \in \mathrm{X}$ with $(\mathrm{gx}, \mathrm{gy}) \in \mathrm{E}(\tilde{\mathrm{G}})$, where $\mathrm{B} \in \mathbb{A}_{+}^{\prime}$ and $\|\mathrm{BA}\|<\frac{1}{\|\mathrm{~A}\|+1}$. Suppose $\mathrm{f}(\mathrm{X}) \subseteq \mathrm{g}(\mathrm{X})$ and $\mathrm{g}(\mathrm{X})$ is a complete subspace of $\mathrm{X}$ with the property $(*)$. Then $\mathrm{f}$ and $\mathrm{g}$ have a point of coincidence in $\mathrm{X}$ if $\mathrm{C}_{\mathrm{g} f} \neq \emptyset$. Moreover, $\mathrm{f}$ and $\mathrm{g}$ have a unique point of coincidence in $\mathrm{X}$ if the graph $\mathrm{G}$ has the property $(* *)$. Furthermore, if $\mathrm{f}$ and $\mathrm{g}$ are weakly compatible, then $\mathrm{f}$ and $\mathrm{g}$ have a unique common fixed point in $\mathrm{X}$.

Proof. It follows from condition (3.5) that $\mathrm{B}(\mathrm{d}(\mathrm{fx}, \mathrm{gy})+\mathrm{d}(\mathrm{fy}, \mathrm{gx}))$ is a positive element.

Suppose that $C_{g f} \neq \emptyset$. We choose an $x_{0} \in C_{g f}$ and keep it fixed. We can construct a sequence $\left(g x_{n}\right)$ such that $g x_{n}=f x_{n-1}, n=1,2,3, \cdots$. Evidently, $\left(g x_{n}, g x_{m}\right) \in E(\tilde{G})$ for $m, n=0,1,2, \cdots$.

For any $n \in \mathbb{N}$, we have by using condition (3.5) and Lemma 2.1(iii) that

$$
\begin{aligned}
\mathrm{d}\left(g x_{n}, g x_{n+1}\right) & =d\left(f x_{n-1}, f x_{n}\right) \\
& \preceq B\left[d\left(f x_{n-1}, g x_{n}\right)+d\left(f x_{n}, g x_{n-1}\right)\right] \\
& =B\left[d\left(f x_{n-1}, f x_{n-1}\right)+d\left(f x_{n}, f x_{n-2}\right)\right] \\
& \preceq B A\left[d\left(f x_{n}, f x_{n-1}\right)+d\left(f x_{n-1}, f x_{n-2}\right)\right] \\
& \left.=B A d\left(g x_{n+1}, g x_{n}\right)+B A d\left(g x_{n}, g x_{n-1}\right)\right]
\end{aligned}
$$

which implies that,

$$
(I-B A) d\left(g x_{n}, g x_{n+1}\right) \preceq B A d\left(g x_{n}, g x_{n-1}\right) .
$$

Now, $A, B \in \mathbb{A}_{+}^{\prime}$ implies that $B A \in \mathbb{A}_{+}^{\prime}$. Since $\|B A\|<\frac{1}{2}$, by Lemma 2.1 it follows that $(I-B A)$ is invertible and $\left\|B A(I-B A)^{-1}\right\|=\left\|(I-B A)^{-1} B A\right\|<1$. Moreover, by Lemma 2.1. $B A \preceq I$ i.e., $I-B A \succeq \theta$. Since $B A \in \mathbb{A}_{+}^{\prime}$, we have $(I-B A) \in \mathbb{A}_{+}^{\prime}$. Furthermore, $(I-B A)^{-1} \in \mathbb{A}_{+}^{\prime}$. By using Lemma 2.1(iv), it follows from (3.6) that

$$
d\left(g x_{n}, g x_{n+1}\right) \preceq(I-B A)^{-1} B A d\left(g x_{n}, g x_{n-1}\right)=\operatorname{td}\left(g x_{n-1}, g x_{n}\right),
$$

where $t=(I-B A)^{-1} B A \in \mathbb{A}_{+}^{\prime}$.

By repeated use of condition (3.7), we get

$$
d\left(g x_{n}, g x_{n+1}\right) \preceq t^{n} d\left(g x_{0}, g x_{1}\right)=t^{n} B_{0},
$$

for all $n \in \mathbb{N}$, where $B_{0}=d\left(g x_{0}, g x_{1}\right) \in \mathbb{A}_{+}$. 
We now prove that if $\|\mathrm{BA}\|<\frac{1}{\|\mathrm{~A}\|+1}$, then $\|\mathrm{t}\|<\frac{1}{\|\mathrm{~A}\|}$.

We have,

$$
\begin{aligned}
\|t\| & =\left\|(I-B A)^{-1} B A\right\| \\
& \leq\left\|(I-B A)^{-1}\right\|\|B A\| \\
& \leq \frac{1}{1-\|B A\|}\|B A\| \\
& <\frac{1}{\|A\|}, \text { since }\|B A\|<\frac{1}{\|A\|+1} .
\end{aligned}
$$

For any $m, n \in \mathbb{N}$ with $m>n$, we have by using condition (3.8) that

$$
\begin{aligned}
\mathrm{d}\left(g x_{n}, g x_{m}\right) \preceq & A\left[d\left(g x_{n}, g x_{n+1}\right)+d\left(g x_{n+1}, g x_{m}\right)\right] \\
\preceq & A d\left(g x_{n}, g x_{n+1}\right)+A^{2} d\left(g x_{n+1}, g x_{n+2}\right)+\cdots \\
& +A^{m-n-1} d\left(g x_{m-2}, g x_{m-1}\right)+A^{m-n-1} d\left(g x_{m-1}, g x_{m}\right) \\
\preceq & A t^{n} B_{0}+A^{2} t^{n+1} B_{0}+A^{3} t^{n+2} B_{0}+\cdots \\
& +A^{m-n-1} t^{m-2} B_{0}+A^{m-n-1} t^{m-1} B_{0} \\
\preceq & \sum_{k=1}^{m-n} A^{k} t^{n+k-1} B_{0}, \text { since } A \succeq I \text { and } A \in \mathbb{A}_{+}^{\prime} \\
\preceq & \sum_{k=1}^{m-n}\left\|A^{k} t^{n+k-1} B_{0}\right\| I \\
\preceq & \left\|B_{0}\right\|\|A\|\|t\|^{n} \sum_{k=1}^{m-n}(\|A\|\|t\|)^{k-1} I \\
\preceq & \left\|B_{0}\right\|\|A\|\|t\|^{n} \frac{1}{1-\|A\|\|t\|} I \\
\rightarrow & \theta \text { as } n \rightarrow \infty .
\end{aligned}
$$

Therefore, $\left(g x_{n}\right)$ is a Cauchy sequence with respect to $\mathbb{A}$. As $g(X)$ is complete, there exists an $u \in g(X)$ such that $\lim _{n \rightarrow \infty} g x_{n}=u=g v$ for some $v \in X$. By property $(*)$, there exists a subsequence $\left(g x_{n_{i}}\right)$ of $\left(g x_{n}\right)$ such that $\left(g x_{n_{i}}, g v\right) \in E(\tilde{G})$ for all $i \geq 1$.

Using condition (3.5), we have

$$
\begin{aligned}
d(f v, g v) & \preceq A\left[d\left(f v, f x_{n_{i}}\right)+d\left(f x_{n_{i}}, g v\right)\right] \\
& \preceq A B\left[d\left(f v, g x_{n_{i}}\right)+d\left(f x_{n_{i}}, g v\right)\right]+A d\left(g x_{n_{i}+1}, g v\right) \\
& \preceq A B A\left[d(f v, g v)+d\left(g v, g x_{n_{i}}\right)\right]+A B d\left(g x_{n_{i}+1}, g v\right)+A d\left(g x_{n_{i}+1}, g v\right)
\end{aligned}
$$

which implies that,

$$
\left(I-B A^{2}\right) d(f v, g v) \preceq B A^{2} d\left(g v, g x_{n_{i}}\right)+A B d\left(g x_{n_{i}+1}, g v\right)+A d\left(g x_{n_{i}+1}, g v\right) .
$$


Since $\left\|B A^{2}\right\|<\frac{\|A\|}{\|A\|+1}<1$, we have $\left(I-B A^{2}\right)^{-1}$ exists. By using Lemma 2.1, it follows that

$$
\begin{aligned}
\mathrm{d}(f v, g v) \preceq & \left(I-B A^{2}\right)^{-1} B A^{2} \mathrm{~d}\left(g v, g x_{n_{i}}\right)+\left(I-B A^{2}\right)^{-1} A B d\left(g x_{n_{i}+1}, g v\right) \\
& +\left(I-B A^{2}\right)^{-1} A d\left(g x_{n_{i}+1}, g v\right) \\
\rightarrow & \theta \text { as } i \rightarrow \infty .
\end{aligned}
$$

This implies that $d(f v, g v)=\theta$ i.e., $f v=g v=u$ and hence $u$ is a point of coincidence of $f$ and $g$.

Finally, to prove the uniqueness of point of coincidence, suppose that there is another point of coincidence $\mathrm{u}^{*}$ in $X$ such that $f x=g x=u^{*}$ for some $x \in X$. By property $(* *)$, we have $\left(u, u^{*}\right) \in E(\tilde{G})$. Then,

$$
\begin{aligned}
d\left(u, u^{*}\right) & =d(f v, f x) \\
& \preceq B[d(f v, g x)+d(f x, g v)] \\
& =B\left[d\left(u, u^{*}\right)+d\left(u, u^{*}\right)\right] \\
& \preceq A B\left[d\left(u, u^{*}\right)+d\left(u, u^{*}\right)\right]
\end{aligned}
$$

which implies that,

$$
d\left(u, u^{*}\right) \preceq(I-A B)^{-1} A B d\left(u, u^{*}\right) .
$$

So, it must be the case that

$$
\begin{aligned}
\left\|d\left(u, u^{*}\right)\right\| & \leq\left\|(I-A B)^{-1} A B d\left(u, u^{*}\right)\right\| \\
& \leq\left\|(I-A B)^{-1} A B\right\|\left\|d\left(u, u^{*}\right)\right\| .
\end{aligned}
$$

Since $\left\|(I-A B)^{-1} A B\right\|<1$, we have $\left\|d\left(u, u^{*}\right)\right\|=0$ i.e., $u=u^{*}$. Therefore, $f$ and $g$ have a unique point of coincidence in $X$.

If $f$ and $g$ are weakly compatible, then by Proposition 2.13 $f$ and $g$ have a unique common fixed point in $X$.

Corollary 3.10. Let $(\mathrm{X}, \mathbb{A}, \mathrm{d})$ be a complete $\mathrm{C}^{*}$-algebra valued $\mathrm{b}$-metric space endowed with a graph $\mathrm{G}$ and the mapping $\mathrm{f}: \mathrm{X} \rightarrow \mathrm{X}$ be such that

$$
d(f x, f y) \preceq B[d(f x, y)+d(f y, x)]
$$

for all $\mathrm{x}, \mathrm{y} \in \mathrm{X}$ with $(\mathrm{x}, \mathrm{y}) \in \mathrm{E}(\tilde{\mathrm{G}})$, where $\mathrm{B} \in \mathbb{A}_{+}^{\prime}$ and $\|\mathrm{BA}\|<\frac{1}{\|\mathrm{~A}\|+1}$. Suppose $(\mathrm{X}, \mathbb{A}, \mathrm{d}, \mathrm{G})$ has the property $(*)$. Then $\mathrm{f}$ has a fixed point in $\mathrm{X}$ if $\mathrm{C}_{\mathrm{f}} \neq \emptyset$. Moreover, $\mathrm{f}$ has a unique fixed point in $\mathrm{X}$ if the graph $\mathrm{G}$ has the property $(* *)$.

Proof. The proof can be obtained from Theorem 3.9 by putting $\mathrm{g}=\mathrm{I}$. 
Corollary 3.11. Let $(\mathrm{X}, \mathbb{A}, \mathrm{d})$ be a $\mathrm{C}^{*}$-algebra valued $\mathrm{b}$-metric space and the mappings $\mathrm{f}, \mathrm{g}$ : $\mathrm{X} \rightarrow \mathrm{X}$ be such that (3.5) holds for all $\mathrm{x}, \mathrm{y} \in \mathrm{X}$, where $\mathrm{B} \in \mathbb{A}_{+}^{\prime}$ and $\|\mathrm{BA}\|<\frac{1}{\|\mathrm{~A}\|+1}$. If $\mathrm{f}(\mathrm{X}) \subseteq \mathrm{g}(\mathrm{X})$ and $\mathrm{g}(\mathrm{X})$ is a complete subspace of $\mathrm{X}$, then $\mathrm{f}$ and $\mathrm{g}$ have a unique point of coincidence in $\mathrm{X}$. Moreover, if $\mathrm{f}$ and $\mathrm{g}$ are weakly compatible, then $\mathrm{f}$ and $\mathrm{g}$ have a unique common fixed point in $\mathrm{X}$.

Proof. The proof can be obtained from Theorem 3.9 by taking $\mathrm{G}=\mathrm{G}_{0}$.

Corollary 3.12. Let $(\mathrm{X}, \mathbb{A}, \mathrm{d})$ be a complete $\mathrm{C}^{*}$-algebra valued $\mathrm{b}$-metric space and the mapping $\mathrm{f}: \mathrm{X} \rightarrow \mathrm{X}$ be such that (3.9) holds for all $\mathrm{x}, \mathrm{y} \in \mathrm{X}$, where $\mathrm{B} \in \mathbb{A}_{+}^{\prime}$ with $\|\mathrm{BA}\|<\frac{1}{\|\mathrm{~A}\|+1}$. Then $\mathrm{f}$ has a unique fixed point in $\mathrm{X}$.

Proof. The proof follows from Theorem 3.9 by taking $\mathrm{G}=\mathrm{G}_{0}$ and $\mathrm{g}=\mathrm{I}$.

Remark 3.13. We observe that Brian Fisher's theorem in a complete metric space can be obtained from Corollary 3.12 by taking $\mathbb{A}=\mathbb{C}, \mathrm{A}=1$. Thus, Theorem 3.9 is a generalization of Brian Fisher's theorem in metric spaces to $\mathrm{C}^{*}$-algebra valued $\mathrm{b}$-metric spaces.

Corollary 3.14. Let $(\mathrm{X}, \mathbb{A}, \mathrm{d})$ be a complete $\mathrm{C}^{*}$-algebra valued $\mathrm{b}$-metric space endowed with a partial ordering $\sqsubseteq$ and the mapping $\mathrm{f}: \mathrm{X} \rightarrow \mathrm{X}$ be such that (3.9) holds for all $\mathrm{x}, \mathrm{y} \in \mathrm{X}$ with $\mathrm{x} \sqsubseteq \mathrm{y}$ or, $\mathrm{y} \sqsubseteq \mathrm{x}$, where $\mathrm{B} \in \mathbb{A}_{+}^{\prime}$ with $\|\mathrm{BA}\|<\frac{1}{\|\mathrm{~A}\|+1}$. Suppose $(\mathrm{X}, \mathbb{A}, \mathrm{d}, \sqsubseteq)$ has the property $(\dagger)$. If there exists $\mathrm{x}_{0} \in \mathrm{X}$ such that $\mathrm{f}^{\mathrm{n}} \mathrm{x}_{0}, \mathrm{f}^{\mathrm{m}} \mathrm{x}_{0}$ are comparable for $\mathrm{m}, \mathrm{n}=0,1,2, \cdots$, then $\mathrm{f}$ has a fixed point in $\mathrm{X}$. Moreover, $\mathrm{f}$ has a unique fixed point in $\mathrm{X}$ if the property (††) holds.

Proof. The proof can be obtained from Theorem 3.9 by taking $\mathrm{G}=\mathrm{G}_{2}$ and $\mathrm{g}=\mathrm{I}$.

Theorem 3.15. Let $(\mathrm{X}, \mathbb{A}, \mathrm{d})$ be a $\mathrm{C}^{*}$-algebra valued $\mathrm{b}$-metric space endowed with a graph $\mathrm{G}$ and the mappings $\mathrm{f}, \mathrm{g}: \mathrm{X} \rightarrow \mathrm{X}$ be such that

$$
d(f x, f y) \preceq B[d(f x, g x)+d(f y, g y)]
$$

for all $\mathrm{x}, \mathrm{y} \in \mathrm{X}$ with $(\mathrm{g} x, \mathrm{gy}) \in \mathrm{E}(\tilde{\mathrm{G}})$, where $\mathrm{B} \in \mathbb{A}_{+}^{\prime}$ and $\|\mathrm{B}\|<\frac{1}{\|\mathrm{~A}\|+1}$. Suppose $\mathrm{f}(\mathrm{X}) \subseteq \mathrm{g}(\mathrm{X})$ and $\mathrm{g}(\mathrm{X})$ is a complete subspace of $\mathrm{X}$ with the property $(*)$. Then $\mathrm{f}$ and $\mathrm{g}$ have a point of coincidence in $\mathrm{X}$ if $\mathrm{C}_{\mathrm{g}} \neq \emptyset$. Moreover, $\mathrm{f}$ and $\mathrm{g}$ have a unique point of coincidence in $\mathrm{X}$ if the graph $\mathrm{G}$ has the property (**). Furthermore, if $\mathrm{f}$ and $\mathrm{g}$ are weakly compatible, then $\mathrm{f}$ and $\mathrm{g}$ have a unique common fixed point in $\mathrm{X}$.

Proof. We observe that $\mathrm{B}(\mathrm{d}(\mathrm{fx}, \mathrm{gx})+\mathrm{d}(\mathrm{fy}, \mathrm{gy}))$ is a positive element.

Suppose that $C_{g f} \neq \emptyset$. We choose an $x_{0} \in C_{g f}$ and keep it fixed. We can construct a sequence $\left(g x_{n}\right)$ such that $g x_{n}=f x_{n-1}, n=1,2,3, \cdots$. Evidently, $\left(g x_{n}, g x_{m}\right) \in E(\tilde{G})$ for $m, n=0,1,2, \cdots$. 
For any $n \in \mathbb{N}$, we have by using condition (3.10) that

$$
\begin{aligned}
\mathrm{d}\left(g x_{n}, g x_{n+1}\right) & =d\left(f x_{n-1}, f x_{n}\right) \\
& \preceq B\left[d\left(f x_{n-1}, g x_{n-1}\right)+d\left(f x_{n}, g x_{n}\right)\right] \\
& =B d\left(g x_{n}, g x_{n-1}\right)+B d\left(g x_{n}, g x_{n+1}\right)
\end{aligned}
$$

which implies that,

$$
(I-B) d\left(g x_{n}, g x_{n+1}\right) \preceq B d\left(g x_{n}, g x_{n-1}\right) .
$$

Since $\mathrm{B} \in \mathbb{A}_{+}^{\prime}$ and $\|\mathrm{B}\|<\frac{1}{2}$, by Lemma 2.1, it follows that $\mathrm{B} \preceq \mathrm{I}$ and $(\mathrm{I}-\mathrm{B})$ is invertible with $\left\|\mathrm{B}(\mathrm{I}-\mathrm{B})^{-1}\right\|=\left\|(\mathrm{I}-\mathrm{B})^{-1} \mathrm{~B}\right\|<1$. Furthermore, $(\mathrm{I}-\mathrm{B}),(\mathrm{I}-\mathrm{B})^{-1} \in \mathbb{A}_{+}^{\prime}$ and so, $(\mathrm{I}-\mathrm{B})^{-1} \mathrm{~B} \in \mathbb{A}_{+}^{\prime}$. Again, by using Lemma 2.1(iv), it follows from condition (3.11) that

$$
\mathrm{d}\left(g x_{n}, g x_{n+1}\right) \preceq(I-B)^{-1} B d\left(g x_{n}, g x_{n-1}\right)=\operatorname{td}\left(g x_{n-1}, g x_{n}\right),
$$

where $t=(I-B)^{-1} B \in \mathbb{A}_{+}^{\prime}$.

By repeated use of condition (3.12), we get

$$
d\left(g x_{n}, g x_{n+1}\right) \preceq t^{n} d\left(g x_{0}, g x_{1}\right)=t^{n} B_{0}
$$

for all $n \in \mathbb{N}$, where $\mathrm{B}_{0}=\mathrm{d}\left(\mathrm{gx_{0 }}, \mathrm{gx_{1 }}\right) \in \mathbb{A}_{+}$.

We now prove that if $\|B\|<\frac{1}{\|A\|+1}$, then $\|t\|<\frac{1}{\|A\|}$. We have,

$$
\begin{aligned}
\|\mathrm{t}\| & =\left\|(\mathrm{I}-\mathrm{B})^{-1} \mathrm{~B}\right\| \\
& \leq\left\|(\mathrm{I}-\mathrm{B})^{-1}\right\|\|\mathrm{B}\| \\
& \leq \frac{1}{1-\|\mathrm{B}\|}\|\mathrm{B}\| \\
& <\frac{1}{\|\mathrm{~A}\|}, \text { since }\|\mathrm{B}\|<\frac{1}{\|A\|+1}
\end{aligned}
$$


For any $\mathrm{m}, \mathrm{n} \in \mathbb{N}$ with $\mathrm{m}>\mathrm{n}$, we have by using condition (3.13) that

$$
\begin{aligned}
\mathrm{d}\left(\mathrm{gx_{n }}, \mathrm{gx_{m }}\right) \preceq & A\left[\mathrm{~d}\left(g x_{n}, g x_{n+1}\right)+\mathrm{d}\left(g x_{n+1}, g x_{m}\right)\right] \\
\preceq & A d\left(g x_{n}, g x_{n+1}\right)+A^{2} d\left(g x_{n+1}, g x_{n+2}\right)+\cdots \\
& +A^{m-n-1} d\left(g x_{m-2}, g x_{m-1}\right)+A^{m-n-1} d\left(g x_{m-1}, g x_{m}\right) \\
\preceq & A t^{n} B_{0}+A^{2} t^{n+1} B_{0}+A^{3} t^{n+2} B_{0}+\cdots \\
& +A^{m-n-1} t^{m-2} B_{0}+A^{m-n-1} t^{m-1} B_{0} \\
\preceq & \sum_{k=1}^{m-n} A^{k} t^{n+k-1} B_{0}, \text { since } A \succeq I \text { and } A \in \mathbb{A}_{+}^{\prime} \\
\preceq & \sum_{k=1}^{m-n}\left\|A^{k} t^{n+k-1} B_{0}\right\| I \\
\preceq & \left\|B_{0}\right\|\|A\|\|t\|^{n} \sum_{k=1}^{m-n}(\|A\|\|t\|)^{k-1} I \\
\preceq & \left\|B_{0}\right\|\|A\|\|t\|^{n} \frac{1}{1-\|A\|\|t\|} I \\
\rightarrow & \theta \text { as } n \rightarrow \infty .
\end{aligned}
$$

Therefore, $\left(g x_{n}\right)$ is a Cauchy sequence with respect to $\mathbb{A}$. By completeness of $g(X)$, there exists an $u \in g(X)$ such that $\lim _{n \rightarrow \infty} g x_{n}=u=g v$ for some $v \in X$. By property $(*)$, there exists a subsequence $\left(g x_{n_{i}}\right)$ of $\left(g x_{n}\right)$ such that $\left(g x_{n_{i}}, g v\right) \in E(\tilde{G})$ for all $i \geq 1$.

Using condition (3.10), we have

$$
\begin{aligned}
d(f v, g v) & \preceq A\left[d\left(f v, f x_{n_{i}}\right)+d\left(f x_{n_{i}}, g v\right)\right] \\
& \preceq A B\left[d(f v, g v)+d\left(f x_{n_{i}}, g x_{n_{i}}\right)\right]+A d\left(g x_{n_{i}+1}, g v\right)
\end{aligned}
$$

which implies that,

$$
(I-A B) d(f v, g v) \preceq A B d\left(g x_{n_{i}+1}, g x_{n_{i}}\right)+A d\left(g x_{n_{i}+1}, g v\right) .
$$

Since $\|A B\|<\frac{\|A\|}{\|A\|+1}<1$, we have $(I-A B)^{-1}$ exists and $(I-A B) \in \mathbb{A}_{+}^{\prime}$. By using Lemma 2.1, it follows that

$$
d(f v, g v) \preceq(I-A B)^{-1} A B d\left(g x_{n_{i}+1}, g x_{n_{i}}\right)+(I-A B)^{-1} A d\left(g x_{n_{i}+1}, g v\right) .
$$

Then,

$$
\begin{aligned}
\|\mathrm{d}(\mathrm{f} v, g v)\| \leq & \left\|(I-A B)^{-1} A B\right\|\left\|d\left(g x_{n_{i}+1}, g x_{n_{i}}\right)\right\| \\
& +\left\|(I-A B)^{-1} A\right\|\left\|d\left(g x_{n_{i}+1}, g v\right)\right\| \\
\leq & \left\|(I-A B)^{-1} A B\right\|\|t\|^{n_{i}}\left\|B_{0}\right\| \\
& +\left\|(I-A B)^{-1} A\right\|\left\|d\left(g x_{n_{i}+1}, g v\right)\right\| \\
\rightarrow & 0 \text { as } i \rightarrow \infty .
\end{aligned}
$$


This implies that $d(f v, g v)=\theta$ i.e., $f v=g v=u$ and hence $u$ is a point of coincidence of $f$ and $g$.

Finally, to prove the uniqueness of point of coincidence, suppose that there is another point of coincidence $u^{*}$ in $X$ such that $f x=g x=u^{*}$ for some $x \in X$. By property $(* *)$, we have $\left(u, u^{*}\right) \in E(\tilde{G})$. Then,

$$
\begin{aligned}
\mathrm{d}\left(\mathrm{u}, \mathrm{u}^{*}\right) & =\mathrm{d}(\mathrm{f} v, f x) \\
& \preceq \mathrm{B}[\mathrm{d}(\mathrm{f} v, \mathrm{~g} v)+\mathrm{d}(\mathrm{f} x, \mathrm{gx})] \\
& =\theta
\end{aligned}
$$

which implies that, $d\left(u, u^{*}\right)=\theta$ i.e., $u=u^{*}$. Therefore, $f$ and $g$ have a unique point of coincidence in $X$.

If $f$ and $g$ are weakly compatible, then by Proposition 2.13 $f$ and $g$ have a unique common fixed point in $X$.

Corollary 3.16. Let $(\mathrm{X}, \mathbb{A}, \mathrm{d})$ be a complete $\mathrm{C}^{*}$-algebra valued $\mathrm{b}$-metric space endowed with a graph $\mathrm{G}$ and the mapping $\mathrm{f}: \mathrm{X} \rightarrow \mathrm{X}$ be such that

$$
d(f x, f y) \preceq B[d(f x, x)+d(f y, y)]
$$

for all $\mathrm{x}, \mathrm{y} \in \mathrm{X}$ with $(\mathrm{x}, \mathrm{y}) \in \mathrm{E}(\tilde{\mathrm{G}})$, where $\mathrm{B} \in \mathbb{A}_{+}^{\prime}$ and $\|\mathrm{B}\|<\frac{1}{\|\mathrm{~A}\|+1}$. Suppose $(\mathrm{X}, \mathbb{A}, \mathrm{d}, \mathrm{G})$ has the property $(*)$. Then $\mathrm{f}$ has a fixed point in $\mathrm{X}$ if $\mathrm{C}_{\mathrm{f}} \neq \emptyset$. Moreover, $\mathrm{f}$ has a unique fixed point in $\mathrm{X}$ if the graph $\mathrm{G}$ has the property $(* *)$.

Proof. The proof can be obtained from Theorem 3.15 by putting $\mathrm{g}=\mathrm{I}$.

Corollary 3.17. Let $(\mathrm{X}, \mathbb{A}, \mathrm{d})$ be a $\mathrm{C}^{*}$-algebra valued $\mathrm{b}$-metric space and the mappings $\mathrm{f}, \mathrm{g}$ : $\mathrm{X} \rightarrow \mathrm{X}$ be such that (3.10) holds for all $\mathrm{x}, \mathrm{y} \in \mathrm{X}$, where $\mathrm{B} \in \mathbb{A}_{+}^{\prime}$ and $\|\mathrm{B}\|<\frac{1}{\|\mathrm{~A}\|+1}$. If $\mathrm{f}(\mathrm{X}) \subseteq \mathrm{g}(\mathrm{X})$ and $\mathrm{g}(\mathrm{X})$ is a complete subspace of $\mathrm{X}$, then $\mathrm{f}$ and $\mathrm{g}$ have a unique point of coincidence in $\mathrm{X}$. Moreover, if $\mathrm{f}$ and $\mathrm{g}$ are weakly compatible, then $\mathrm{f}$ and $\mathrm{g}$ have a unique common fixed point in $\mathrm{X}$.

Proof. The proof can be obtained from Theorem 3.15 by taking $\mathrm{G}=\mathrm{G}_{0}$.

Corollary 3.18. Let $(\mathrm{X}, \mathbb{A}, \mathrm{d})$ be a complete $\mathrm{C}^{*}$-algebra valued $\mathrm{b}$-metric space and the mapping $\mathrm{f}: \mathrm{X} \rightarrow \mathrm{X}$ be such that [3.14) holds for all $\mathrm{x}, \mathrm{y} \in \mathrm{X}$, where $\mathrm{B} \in \mathbb{A}_{+}^{\prime}$ with $\|\mathrm{B}\|<\frac{1}{\|\mathrm{~A}\|+1}$. Then $\mathrm{f}$ has a unique fixed point in $\mathrm{X}$.

Proof. The proof follows from Theorem 3.15 by taking $\mathrm{G}=\mathrm{G}_{0}$ and $\mathrm{g}=\mathrm{I}$. 
Remark 3.19. We observe that Kannan's fixed point theorem in a complete metric space can be obtained from Corollary 3.18 by taking $\mathbb{A}=\mathbb{C}, A=1$. Thus, Theorem 3.15 is a generalization of Kannan's fixed point theorem in metric spaces to $\mathrm{C}^{*}$-algebra valued $\mathrm{b}$-metric spaces.

Corollary 3.20. Let $(\mathrm{X}, \mathbb{A}, \mathrm{d})$ be a complete $\mathrm{C}^{*}$-algebra valued $\mathrm{b}$-metric space endowed with a partial ordering $\sqsubseteq$ and the mapping $\mathrm{f}: \mathrm{X} \rightarrow \mathrm{X}$ be such that (3.14) holds for all $\mathrm{x}, \mathrm{y} \in \mathrm{X}$ with $\mathrm{x} \sqsubseteq \mathrm{y}$ or, $\mathrm{y} \sqsubseteq \mathrm{x}$, where $\mathrm{B} \in \mathbb{A}_{+}^{\prime}$ with $\|\mathrm{B}\|<\frac{1}{\|\mathrm{~A}\|+1}$. Suppose $(\mathrm{X}, \mathrm{A}, \mathrm{d}, \sqsubseteq)$ has the property $(\dagger)$. If there exists $\mathrm{x}_{0} \in \mathrm{X}$ such that $\mathrm{f}^{\mathrm{n}} \mathrm{x}_{0}, \mathrm{f}^{\mathrm{m}} \mathrm{x}_{0}$ are comparable for $\mathrm{m}, \mathrm{n}=0,1,2, \cdots$, then $\mathrm{f}$ has a fixed point in $\mathrm{X}$. Moreover, $\mathrm{f}$ has a unique fixed point in $\mathrm{X}$ if the property (††) holds.

Proof. The proof can be obtained from Theorem 3.15 by taking $\mathrm{G}=\mathrm{G}_{2}$ and $\mathrm{g}=\mathrm{I}$.

We furnish some examples in favour of our results.

Example 3.21. Let $\mathrm{X}=\mathbb{R}$ and $\mathrm{B}(\mathrm{H})$ be the set of all bounded linear operators on a Hilbert space $\mathrm{H}$. Define $\mathrm{d}: \mathrm{X} \times \mathrm{X} \rightarrow \mathrm{B}(\mathrm{H})$ by $\mathrm{d}(\mathrm{x}, \mathrm{y})=|\mathrm{x}-\mathrm{y}|^{3}$ I for all $\mathrm{x}, \mathrm{y} \in \mathrm{X}$, where $\mathrm{I}$ is the identity operator on $\mathrm{H}$. Then $(\mathrm{X}, \mathrm{B}(\mathrm{H}), \mathrm{d})$ is a complete $\mathrm{C}^{*}$-algebra valued $\mathrm{b}$-metric space with the coefficient $\mathrm{A}=4 \mathrm{I}$. Let $\mathrm{G}$ be a digraph such that $\mathrm{V}(\mathrm{G})=\mathrm{X}$ and $\mathrm{E}(\mathrm{G})=\Delta \cup\left\{\left(\frac{1}{n}, 0\right): \mathrm{n}=1,2,3 \cdots\right\}$.

Let $\mathrm{f}, \mathrm{g}: \mathrm{X} \rightarrow \mathrm{X}$ be defined by

$$
\begin{aligned}
f x & =\frac{x}{5}, \text { if } x \neq \frac{4}{5} \\
& =1, \text { if } x=\frac{4}{5}
\end{aligned}
$$

and $\mathrm{gx}=2 \mathrm{x}$ for all $\mathrm{x} \in \mathrm{X}$. Obviously, $\mathrm{f}(\mathrm{X}) \subseteq \mathrm{g}(\mathrm{X})=\mathrm{X}$.

$$
\text { If } \mathrm{x}=0, \mathrm{y}=\frac{1}{2 \mathrm{n}}, \mathrm{n}=1,2,3, \cdots \text {, then } \mathrm{gx}=0, \mathrm{gy}=\frac{1}{\mathrm{n}} \text { and } \text { so }(\mathrm{gx}, \mathrm{gy}) \in \mathrm{E}(\tilde{\mathrm{G}}) \text {. }
$$

For $\mathrm{x}=0, \mathrm{y}=\frac{1}{2 \mathrm{n}}$, we have

$$
\begin{aligned}
d(f x, f y) & =d\left(0, \frac{1}{10 n}\right) \\
& =\frac{1}{10^{3} \cdot n^{3}} I \\
& \prec \frac{1}{25 n^{3}} I \\
& =\frac{1}{25} d(g x, g y) \\
& =B^{*} d(g x, g y) B
\end{aligned}
$$

where $\mathrm{B}=\frac{1}{5} \mathrm{I} \in \mathrm{B}(\mathrm{H})$. 
Therefore,

$$
d(f x, f y) \preceq B^{*} d(g x, g y) B
$$

for all $\mathrm{x}, \mathrm{y} \in \mathrm{X}$ with $(\mathrm{gx}, \mathrm{gy}) \in \mathrm{E}(\tilde{\mathrm{G}})$, where $\mathrm{B} \in \mathrm{B}(\mathrm{H})$ and $\|\mathrm{B}\|^{2}<\frac{1}{\|\mathrm{~A}\|}$. We can verify that

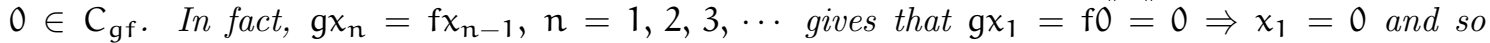
$\mathrm{gx}_{2}=\mathrm{fx} \mathrm{x}_{1}=0 \Rightarrow \mathrm{x}_{2}=0$. Proceeding in this way, we get $\mathrm{gx} \mathrm{n}=0$ for $\mathrm{n}=0,1,2, \cdots$ and hence $\left(g x_{n}, g x_{m}\right)=(0,0) \in E(\tilde{G})$ for $\mathrm{m}, \mathrm{n}=0,1,2, \cdots$.

Also, any sequence $\left(\mathrm{gx}_{\mathrm{n}}\right)$ with the property $\left(\mathrm{gx_{n }}, \mathrm{gx_{n+1 }}\right) \in \mathrm{E}(\tilde{\mathrm{G}})$ must be either a constant sequence or a sequence of the following form

$$
\begin{aligned}
g x_{n} & =0, \text { if } n \text { is odd } \\
& =\frac{1}{n}, \text { if } n \text { is even }
\end{aligned}
$$

where the words 'odd' and 'even' are interchangeable. Consequently it follows that property $(*)$ holds. Furthermore, $\mathrm{f}$ and $\mathrm{g}$ are weakly compatible. Thus, we have all the conditions of Theorem 3.2 and 0 is the unique common fixed point of $\mathrm{f}$ and $\mathrm{g}$ in $\mathrm{X}$.

Remark 3.22. It is worth mentioning that weak compatibility condition in Theorem 3.2 cannot be relaxed. In Example 3.21, if we take $\mathrm{gx}=2 \mathrm{x}-9$ for all $\mathrm{x} \in \mathrm{X}$ instead of $\mathrm{gx}=2 \mathrm{x}$, then $5 \in \mathrm{C}_{\mathrm{g} f}$ and $\mathrm{f}(5)=\mathrm{g}(5)=1$ but $\mathrm{g}(\mathrm{f}(5)) \neq \mathrm{f}(\mathrm{g}(5))$ i.e., $\mathrm{f}$ and $\mathrm{g}$ are not weakly compatible. However, all other conditions of Theorem 3.2 are satisfied. We observe that 1 is the unique point of coincidence of $\mathrm{f}$ and $\mathrm{g}$ without being any common fixed point.

Remark 3.23. In Example 3.21, $\mathrm{f}$ is a $\mathrm{C}^{*}$-algebra valued $\mathrm{G}$-contraction but it is not a $\mathrm{C}^{*}$ algebra valued contraction. In fact, for $\mathrm{x}=\frac{4}{5}, \mathrm{y}=0$, we have

$$
\begin{aligned}
d(f x, f y) & =d(1,0) \\
& =I \\
& =\frac{125}{64} \cdot \frac{64}{125} I \\
& =\frac{125}{64} d(x, y) \\
& \succ B^{*} d(x, y) B
\end{aligned}
$$

for any $\mathrm{B} \in \mathrm{B}(\mathrm{H})$ with $\|\mathrm{B}\|^{2}<\frac{1}{\|\mathrm{~A}\|}$. This implies that $\mathrm{f}$ is not a $\mathrm{C}^{*}$-algebra valued contraction.

The following example shows that property $(*)$ is necessary in Theorem 3.2 .

Example 3.24. Let $\mathrm{X}=[0, \infty)$ and $\mathrm{B}(\mathrm{H})$ be the set of all bounded linear operators on a Hilbert space $\mathrm{H}$. Define $\mathrm{d}: \mathrm{X} \times \mathrm{X} \rightarrow \mathrm{B}(\mathrm{H})$ by $\mathrm{d}(x, y)=|x-y|^{3}$ I for all $\mathrm{x}, \mathrm{y} \in \mathrm{X}$, where $\mathrm{I}$ is the identity operator on $\mathrm{H}$. Then $(\mathrm{X}, \mathrm{B}(\mathrm{H}), \mathrm{d})$ is a complete $\mathrm{C}^{*}$-algebra valued $\mathrm{b}$-metric space with the coefficient 
$\mathrm{A}=4 \mathrm{I}$. Let $\mathrm{G}$ be a digraph such that $\mathrm{V}(\mathrm{G})=\mathrm{X}$ and $\mathrm{E}(\mathrm{G})=\Delta \cup\{(\mathrm{x}, \mathrm{y}):(\mathrm{x}, \mathrm{y}) \in(0,1] \times(0,1], x \geq \mathrm{y}\}$.

Let $\mathrm{f}, \mathrm{g}: \mathrm{X} \rightarrow \mathrm{X}$ be defined by

$$
\begin{aligned}
f x & =\frac{x}{6}, \text { if } x \neq 0 \\
& =1, \text { if } x=0
\end{aligned}
$$

and $\mathrm{gx}=\frac{\mathrm{x}}{2}$ for all $\mathrm{x} \in \mathrm{X}$. Obviously, $\mathrm{f}(\mathrm{X}) \subseteq \mathrm{g}(\mathrm{X})=\mathrm{X}$.

For $\mathrm{x}, \mathrm{y} \in \mathrm{X}$ with $(\mathrm{g} x, \mathrm{gy}) \in \mathrm{E}(\tilde{\mathrm{G}})$, we have

$$
\begin{aligned}
d(f x, f y) & =\frac{1}{27} d(g x, g y) \\
& \preceq \frac{1}{9} d(g x, g y) \\
& =B^{*} d(g x, g y) B
\end{aligned}
$$

where $\mathrm{B}=\frac{1}{3} \mathrm{I} \in \mathrm{B}(\mathrm{H})$ with $\|\mathrm{B}\|^{2}<\frac{1}{\|\mathrm{~A}\|}$.

We see that $\mathrm{f}$ and $\mathrm{g}$ have no point of coincidence in $\mathrm{X}$. We now verify that the property $(*)$ does not hold. In fact, $\left(\mathrm{g} \mathrm{x}_{\mathrm{n}}\right)$ is a sequence in $\mathrm{X}$ with $\mathrm{g} \mathrm{x}_{\mathrm{n}} \rightarrow 0$ and $\left(\mathrm{g} \mathrm{x}_{\mathrm{n}}, \mathrm{g} \mathrm{x}_{\mathrm{n}+1}\right) \in \mathrm{E}(\tilde{\mathrm{G}})$ for all $\mathrm{n} \in \mathbb{N}$ where $\mathrm{x}_{\mathrm{n}}=\frac{2}{\mathrm{n}}$. But there exists no subsequence $\left(\mathrm{gx_{ \textrm {n } _ { \mathrm { i } } }}\right)$ of $\left(\mathrm{gx_{ \textrm {n } }}\right)$ such that $\left(\mathrm{gx_{n_{i } }}, 0\right) \in \mathrm{E}(\tilde{\mathrm{G}})$.

Example 3.25. Let $\mathrm{X}=\mathbb{R}$ and $\mathrm{B}(\mathrm{H})$ be the set of all bounded linear operators on a Hilbert space $\mathrm{H}$. Choose a positive operator $\mathrm{T} \in \mathrm{B}(\mathrm{H})$. Define $\mathrm{d}: \mathrm{X} \times \mathrm{X} \rightarrow \mathrm{B}(\mathrm{H})$ by $\mathrm{d}(\mathrm{x}, \mathrm{y})=|\mathrm{x}-\mathrm{y}|^{5} \mathrm{~T}$ for all $\mathrm{x}, \mathrm{y} \in \mathrm{X}$. Then $(\mathrm{X}, \mathrm{B}(\mathrm{H}), \mathrm{d})$ is a complete $\mathrm{C}^{*}$-algebra valued $\mathrm{b}$-metric space with the coefficient $\mathrm{A}=16 \mathrm{I}$. Let $\mathrm{f}, \mathrm{g}: \mathrm{X} \rightarrow \mathrm{X}$ be defined by

$$
\begin{aligned}
f x & =2, \text { if } x \neq 5 \\
& =3, \text { if } x=5
\end{aligned}
$$

and $\mathrm{gx}=3 \mathrm{x}-4$ for all $\mathrm{x} \in \mathrm{X}$. Obviously, $\mathrm{f}(\mathrm{X}) \subseteq \mathrm{g}(\mathrm{X})=\mathrm{X}$.

Let $\mathrm{G}$ be a digraph such that $\mathrm{V}(\mathrm{G})=\mathrm{X}$ and $\mathrm{E}(\mathrm{G})=\Delta \cup\{(2,3),(3,5)\}$. If $\mathrm{x}=2, \mathrm{y}=\frac{7}{3}$, then $\mathrm{gx}=2, \mathrm{gy}=3$ and so $(\mathrm{gx}, \mathrm{gy}) \in \mathrm{E}(\tilde{\mathrm{G}})$.

Again, if $\mathrm{x}=\frac{7}{3}, \mathrm{y}=3$, then $\mathrm{gx}=3$, gy $=5$ and so $(\mathrm{gx}, \mathrm{gy}) \in \mathrm{E}(\tilde{\mathrm{G}})$.

It is easy to verify that condition (3.5) of Theorem 3.9 holds for all $\mathrm{x}, \mathrm{y} \in \mathrm{X}$ with ( $\mathrm{gx}, \mathrm{gy}) \in \mathrm{E}(\tilde{\mathrm{G}})$. Furthermore, $2 \in \mathrm{C}_{\mathrm{gf}}$ i.e., $\mathrm{C}_{\mathrm{g} f} \neq \emptyset, \mathrm{f}$ and $\mathrm{g}$ are weakly compatible, and $(\mathrm{X}, \mathrm{B}(\mathrm{H}), \mathrm{d}, \mathrm{G})$ has the property $(*)$. Thus, all the conditions of Theorem 3.9 are satisfied and 2 is the unique common fixed point of $\mathrm{f}$ and $\mathrm{g}$ in $\mathrm{X}$.

Remark 3.26. It is observed that in Example 3.25, $\mathrm{f}$ is not a Fisher G-contraction. In fact, 
for $x=3, y=5$, we have

$$
\begin{aligned}
B[d(f x, y)+d(f y, x)] & =B[d(2,5)+d(3,3)] \\
& =243 B T \\
& =\frac{243}{16} B A T \\
& =\frac{243}{16 \times 17} 17 B A T \\
& \prec T \\
& =d(f x, f y)
\end{aligned}
$$

for any $\mathrm{B} \in \mathrm{B}(\mathrm{H})_{+}^{\prime}$ with $\|\mathrm{BA}\|<\frac{1}{\|\mathrm{~A}\|+1}$. This implies that $\mathrm{f}$ is not a Fisher $\mathrm{G}$-contraction.

The following example supports our Theorem 3.15 .

Example 3.27. Let $\mathrm{X}=[0, \infty)$ and $\mathrm{B}(\mathrm{H})$ be the set of all bounded linear operators on a Hilbert space $\mathrm{H}$. Choose a positive operator $\mathrm{T} \in \mathrm{B}(\mathrm{H})$. Define $\mathrm{d}: \mathrm{X} \times \mathrm{X} \rightarrow \mathrm{B}(\mathrm{H})$ by $\mathrm{d}(\mathrm{x}, \mathrm{y})=|\mathrm{x}-\mathrm{y}|^{2} \mathrm{~T}$ for all $\mathrm{x}, \mathrm{y} \in \mathrm{X}$. Then $(\mathrm{X}, \mathrm{B}(\mathrm{H}), \mathrm{d})$ is a complete $\mathrm{C}^{*}$-algebra valued $\mathrm{b}$-metric space with the coefficient $\mathrm{A}=2 \mathrm{I}$. Let $\mathrm{G}$ be a digraph such that $\mathrm{V}(\mathrm{G})=\mathrm{X}$ and $\mathrm{E}(\mathrm{G})=\Delta \cup\left\{\left(4^{\mathrm{t}} \mathrm{x}, 4^{\mathrm{t}}(\mathrm{x}+1)\right): \mathrm{x} \in \mathrm{X}\right.$ with $\mathrm{x} \geq$ $2, \mathrm{t}=0,1,2, \cdots\}$.

Let $\mathrm{f}, \mathrm{g}: \mathrm{X} \rightarrow \mathrm{X}$ be defined by $\mathrm{f} x=4 \mathrm{x}$ and $\mathrm{gx}=16 \mathrm{x}$ for all $\mathrm{x} \in \mathrm{X}$. Clearly, $\mathrm{f}(\mathrm{X})=\mathrm{g}(\mathrm{X})=\mathrm{X}$.

$$
\text { If } \mathrm{x}=4^{\mathrm{t}-2} z, \mathrm{y}=4^{\mathrm{t}-2}(z+1) \text {, then } \mathrm{gx}=4^{\mathrm{t}} z, g y=4^{\mathrm{t}}(z+1) \text { and so }(\mathrm{gx}, \mathrm{gy}) \in \mathrm{E}(\tilde{\mathrm{G}}) \text { for all }
$$
$z \geq 2$.

$$
\text { For } x=4^{\mathrm{t}-2} z, \begin{aligned}
& \mathrm{y}=4^{\mathrm{t}-2}(z+1), z \geq 2 \text { with } \mathrm{B}=\frac{1}{117} \mathrm{I} \text {, we have } \\
& \qquad \begin{aligned}
\mathrm{d}(\mathrm{f} x, \mathrm{fy}) & =\mathrm{d}\left(4^{\mathrm{t}-1} z, 4^{\mathrm{t}-1}(z+1)\right) \\
& =4^{2 \mathrm{t}-2} \mathrm{~T} \\
& \preceq \frac{1}{117} 4^{2 \mathrm{t}-2}\left(18 z^{2}+18 z+9\right) \mathrm{T} \\
& =\frac{1}{117}\left[\mathrm{~d}\left(4^{\mathrm{t}-1} z, 4^{\mathrm{t}} z\right)+\mathrm{d}\left(4^{\mathrm{t}-1}(z+1), 4^{\mathrm{t}}(z+1)\right)\right] \\
& =\mathrm{B}[\mathrm{d}(\mathrm{f} x, g x)+\mathrm{d}(\mathrm{fy}, \mathrm{gy})] .
\end{aligned}
\end{aligned}
$$

Thus, condition (3.10) is satisfied for all $\mathrm{x}, \mathrm{y} \in \mathrm{X}$ with $(\mathrm{gx}, \mathrm{gy}) \in \mathrm{E}(\tilde{\mathrm{G}})$. It is easy to verify that $0 \in \mathrm{C}_{\mathrm{gf}}$. Also, any sequence $\left(\mathrm{gx_{ \textrm {n } }}\right)$ with $\mathrm{gx_{ \textrm {n } }} \rightarrow \mathrm{x}$ and $\left(\mathrm{g} \mathrm{x}_{\mathrm{n}}, \mathrm{g} \mathrm{x}_{\mathrm{n}+1}\right) \in \mathrm{E}(\tilde{\mathrm{G}})$ must be a constant sequence and hence property $(*)$ holds. Furthermore, $\mathrm{f}$ and $\mathrm{g}$ are weakly compatible. Thus, we have all the conditions of Theorem 3.15 and 0 is the unique common fixed point of $\mathrm{f}$ and $\mathrm{g}$ in $\mathrm{X}$.

Remark 3.28. It is easy to observe that in Example 3.27, $\mathrm{f}$ is a $\mathrm{C}^{*}$-algebra valued $\mathrm{G}-$ Kannan operator with $\mathrm{B}=\frac{16}{117} \mathrm{I}$. But $\mathrm{f}$ is not a $\mathrm{C}^{*}$-algebra valued Kannan operator because, if $\mathrm{x}=4, \mathrm{y}=0$, 
then for any arbitrary $\mathrm{B} \in \mathrm{B}(\mathrm{H})_{+}^{\prime}$ with $\|\mathrm{B}\|<\frac{1}{\|\mathrm{~A}\|+1}=\frac{1}{3}$ (which implies $3 \mathrm{~B} \prec \mathrm{I}$ ), we have

$$
\begin{aligned}
B[d(f x, x)+d(f y, y)] & =B[d(f 4,4)+d(f 0,0)] \\
& =144 B T \\
& =\frac{144}{3 \times 256}(3 B)(256 \mathrm{~T}) \\
& \prec 256 \mathrm{~T} \\
& =d(f x, f y) .
\end{aligned}
$$

\section{References}

[1] A. Aghajani, M. Abbas and J. R. Roshan, Common fixed point of generalized weak contractive mappings in partially ordered b-metric spaces, Math. Slovaca, 64, 2014, 941-960.

[2] M. Abbas and G. Jungck, Common fixed point results for noncommuting mappings without continuity in cone metric spaces, J. Math. Anal. Appl., 341, 2008, 416-420.

[3] M. R. Alfuraidan, M. A. Khamsi, Caristi fixed point theorem in metric spaces with a graph, Abstract and Applied Analysis, vol. 2014, Article ID 303484.

[4] I.A.Bakhtin, The contraction mapping principle in almost metric spaces, Funct. Anal.,Gos. Ped. Inst. Unianowsk, 30, 1989, 26-37.

[5] S. Banach, Sur les opérations dans les ensembles abstraits et leur application aux équations intégrales, Fund. Math., 3, 1922, 133-181.

[6] M. Boriceanu, Strict fixed point theorems for multivalued operators in b-metric spaces, Int. J. Mod. Math., 4, 2009, 285-301.

[7] J. A. Bondy and U. S. R. Murty, Graph theory with applications, American Elsevier Publishing Co., Inc., New York, 1976.

[8] I. Beg, A. R. Butt, S. Radojevic, The contraction principle for set valued mappings on a metric space with a graph, Comput. Math. Appl., 60, 2010, 1214-1219.

[9] F. Bojor, Fixed point of $\varphi$-contraction in metric spaces endowed with a graph, Annala of the University of Cralova, Mathematics and Computer Science Series, 37, 2010, 85-92.

[10] F. Bojor, Fixed points of Kannan mappings in metric spaces endowed with a graph, An. St. Univ. Ovidius Constanta, 20, 2012, 31-40.

[11] S. Czerwik, Contraction mappings in b-metric spaces, Acta Math. Inform. Univ. Ostrav, 1, 1993, 5-11.

[12] G. Chartrand, L. Lesniak, and P. Zhang, Graph and digraph, CRC Press, New York, NY, USA, 2011. 
[13] M. Cosentino, P. Salimi, P. Vetro, Fixed point results on metric-type spaces, Acta Math. Sci. Ser. B Engl. Ed., 34, 2014, 1237-1253.

[14] R. Douglas, Banach algebra techniques in operator theory, Springer, Berlin, 1998.

[15] F. Echenique, A short and constructive proof of Tarski's fixed point theorem, Internat. J. Game Theory, 33, 2005, 215-218.

[16] R. Espinola and W. A. Kirk, Fixed point theorems in R-trees with applications to graph theory, Topology Appl., 153, 2006, 1046-1055.

[17] J. I. Gross and J. Yellen, Graph theory and its applications, CRC Press, New York, NY, USA, 1999.

[18] N. Hussain, D. Dorić, Z. Kadelburg, S. Radenović, Suzuki-type fixed point results in metric type spaces, Fixed Point Theory Appl., 2012, 2012:126, doi:10.1186/1687-1812-2012-126.

[19] G. Jungck, Common fixed points for noncontinuous nonself maps on non-metric spaces, Far East J. Math. Sci., 4, 1996, 199-215.

[20] J. Jachymski, The contraction principle for mappings on a metric space with a graph, Proc. Amer. Math. Soc., 136, 2008, 1359-1373.

[21] Z. Ma, L. Jiang, $C^{*}$-algebra-valued b-metric spaces and related fixed point theorems, Fixed Point Theory and Applications, 2015, 2015:222.

[22] Z. Ma, L. Jiang and H. Sun, C*-algebra-valued metric spaces and related fixed point theorems, Fixed Point Theory and Applications, 2014, 2014:206.

[23] G. Murphy, C*-Algebra and operator theory, Academic Press, London, 1990.

[24] S. K. Mohanta, Some Fixed Point Theorems in Cone Modular Spaces with a Graph, Bolletino dellUnione Matematica Italiana, 2016, DOI 10.1007/s40574-016-0086-9.

[25] S. K. Mohanta, Some fixed point theorems using wt-distance in b-metric spaces, Fasciculi Mathematici, no. 54, 2015, 125-140.

[26] J. J. Nieto and R. Rodríguez-López, Existence and uniqueness of fixed point in partially ordered sets and applications to ordinary differential equations, Acta Math. Sinica, Englosh Ser., 2007, 2205-2212.

[27] D. Reem, S. Reich, A. J. Zaslavski, Two results in metric fixed point theory, J. Fixed Point Theory Appl., 1, 2007, 149-157. 